\title{
Machine Learning for Design Optimization of Electromagnetic Devices: Recent Developments and Future Directions
}

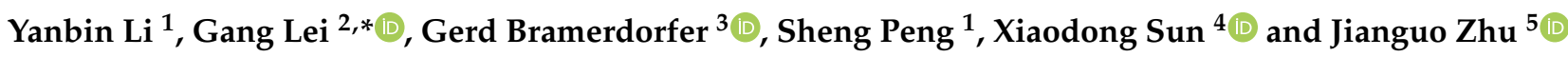 \\ 1 School of Electronic and Information, Zhongyuan University of Technology, Zhengzhou 450007, China;

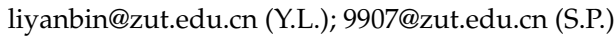 \\ 2 School of Electrical and Data Engineering, University of Technology Sydney, Ultimo, NSW 2007, Australia \\ 3 Department of Electrical Drives and Power Electronics, Johannes Kepler University Linz, Linz 4040, Austria; \\ gerd.bramerdorfer@jku.at \\ 4 Automotive Engineering Research Institute, Jiangsu University, Zhenjiang 212013, China; xdsun@ujs.edu.cn \\ 5 School of Electrical and Information Engineering, The University of Sydney, Sydney, NSW 2006, Australia; \\ jianguo.zhu@sydney.edu.au \\ * Correspondence: gang.lei@uts.edu.au
}

check for

updates

Citation: Li, Y.; Lei, G.;

Bramerdorfer, G.; Peng, S.; Sun, X.;

Zhu, J. Machine Learning for Design

Optimization of Electromagnetic

Devices: Recent Developments and

Future Directions. Appl. Sci. 2021, 11,

1627. https://doi.org/10.3390/

app11041627

Academic Editor:

Dimitrios Zografopoulos

Received: 31 December 2020

Accepted: 8 February 2021

Published: 11 February 2021

Publisher's Note: MDPI stays neutral with regard to jurisdictional claims in published maps and institutional affiliations.

Copyright: (C) 2021 by the authors. Licensee MDPI, Basel, Switzerland. This article is an open access article distributed under the terms and conditions of the Creative Commons Attribution (CC BY) license (https:/ / creativecommons.org/licenses/by/ $4.0 /)$.

\begin{abstract}
This paper reviews the recent developments of design optimization methods for electromagnetic devices, with a focus on machine learning methods. First, the recent advances in multi-objective, multidisciplinary, multilevel, topology, fuzzy, and robust design optimization of electromagnetic devices are overviewed. Second, a review is presented to the performance prediction and design optimization of electromagnetic devices based on the machine learning algorithms, including artificial neural network, support vector machine, extreme learning machine, random forest, and deep learning. Last, to meet modern requirements of high manufacturing/production quality and lifetime reliability, several promising topics, including the application of cloud services and digital twin, are discussed as future directions for design optimization of electromagnetic devices.
\end{abstract}

Keywords: electromagnetic devices; electrical machines; optimization methods; machine learning; deep learning; reliability; topology optimization; robust design

\section{Introduction}

Electromagnetic devices have been widely employed in many domestic appliances, biomedical instruments, and industrial equipment and systems, such as electrical drive systems for air conditioners, artificial hearts, electric vehicles (EVs), and more electric aircraft, wireless power transmission systems for mobile and EV battery charging, and superconducting magnetic energy storage (SMES) for power systems. To meet the design specifications and improve their performance, such as high efficiency, high power density, and high resource efficiency, optimization is always necessary in the design process. Design optimization of electromagnetic devices has been an active research topic in several international conferences, like COMPUMAG and CEFC. Through extensive research work, many design optimization methods have been employed/developed for electromagnetic devices, including multi-objective, multilevel, and multidisciplinary design optimization methods [1-7]. The performance of electromagnetic devices can be improved by using these methods.

As the number of design parameters/objectives and the complexity of analysis models increase, high optimization efficiency becomes a serious challenge for many design scenarios, e.g., the multidisciplinary design optimization of machines and drive systems for EVs and magnetic levitations (maglevs). The computation costs are huge in many situations due to the high dimension of the optimization problem and the complex multi-physics analysis, e.g., the optimization of a high-speed permanent magnet motor with 10 parameters, 3 objectives, and multi-physics analysis of electromagnetic, thermal, and rotor dynamics [8,9]. Therefore, 
how to improve the optimization efficiency (or reduce the computation cost) is a challenge for efficient design optimization of many electromagnetic devices.

Furthermore, the practical performance of electromagnetic devices is affected significantly by the inevitable material diversities and uncertainties in the manufacturing or production process. To improve the manufacturing quality of the optimized electromagnetic devices, design optimization in the presence of uncertainties should be conducted at the early stage of the development. From the perspective of industrial production, the performance of a good design of an electromagnetic device, like a transformer, should not be sensitive to those uncertainties. To achieve this goal, reliability-based and robust optimizations have attracted significant research attention recently, especially when the industrial big data about the material and manufacturing process are considered [6,10-15]. These topics are of ever-growing significance for smart manufacturing in the context of industry 4.0. However, the application of multidisciplinary analysis and/or industrial big data also brings many challenges to the design optimization process and degrades the optimization performance with conventional optimization methods. Advanced technologies, such as machine learning and cloud computing, will greatly improve the handling of these design optimization problems.

This paper reviews the recent developments in design optimization of electromagnetic devices, with a focus on machine learning methods. Compared to the current state of the art, this review has three new contributions. First, this review covers more types of electromagnetic devices, instead of specific types, like electrical machines and antennas $[4,5,7,13,14]$. Second, besides the review of recent developments in typical optimization methods, such as multiobjective and multidisciplinary optimizations, this work reviews the topology optimization, fuzzy optimization, and new optimization strategies like space-reduction strategy. Third, a systematic review of machine learning algorithms is presented, and four promising research directions are proposed to integrate these algorithms with other emerging technologies like digital twin.

The remainder of this paper is organized as follows. Section 2 presents an overview of the recent advances in design optimization of electromagnetic devices, including multiobjective, multidisciplinary, multilevel, topology, and robust optimization methods. Three examples are investigated, including superconducting magnetic energy storage (SMES), high-frequency transformers, and permanent magnet (PM) motors. Section 3 reviews the design optimization of electromagnetic devices based on machine learning methods, with two examples. Section 4 discusses several promising topics as future directions for this research field, followed by the conclusion.

\section{An Overview of Recent Advances in Design Optimization of Electromagnetic Devices}

Design optimization of electromagnetic devices has been an active research topic for many years. Many design optimization methods have been developed through extensive research work worldwide. To compare the performance of different methods, some benchmark works have been developed in International Compumag Society (ICS), like TEAM problems $[6,11,12,16-18]$. Some papers reviewed popular design optimization methods of several types of electromagnetic devices, such as electrical machines [4-6,13,14], and antennas [7]. This section presents an overview of the recent advances in design optimization of electromagnetic devices, including multi-objective, multidisciplinary, multilevel, topology, and robust optimization methods. Section 2.1 starts with the deterministic design optimization (without any consideration of uncertainties).

\subsection{Deterministic Design Optimization}

A generic optimization model of the following form can be defined to the multiobjective optimization of electromagnetic devices.

$$
\begin{array}{cl}
\min : & \left\{f_{i}(\mathbf{x}), i=1,2, \ldots, p\right\} \\
\mathrm{s.t.} & g_{j}(\mathbf{x}) \leq 0, j=1,2, \ldots, m \\
& \mathbf{x}_{l} \leq \mathbf{x} \leq \mathbf{x}_{u}
\end{array}
$$


where $p$ and $m$ are the numbers of objectives, $f_{i}(\mathbf{x})$, and constraints, $g_{j}(\mathbf{x})$, respectively. $\mathbf{x}$ is a vector of design parameters, and $\mathbf{x}_{l}$ and $\mathbf{x}_{u}$ are vectors of the lower and upper boundaries of $\mathbf{x}$. This model will be simplified as a single-objective problem if $p$ is equal to 1 .

The detailed forms of $\mathbf{x}, f(\mathbf{x})$, and $g(\mathbf{x})$ depend on the specific type and application of an electromagnetic device. Figure 1 illustrates three popular applications. They are a SMES, a high-frequency transformer, and a surface-mounted permanent magnet synchronous motor (SPMSM).

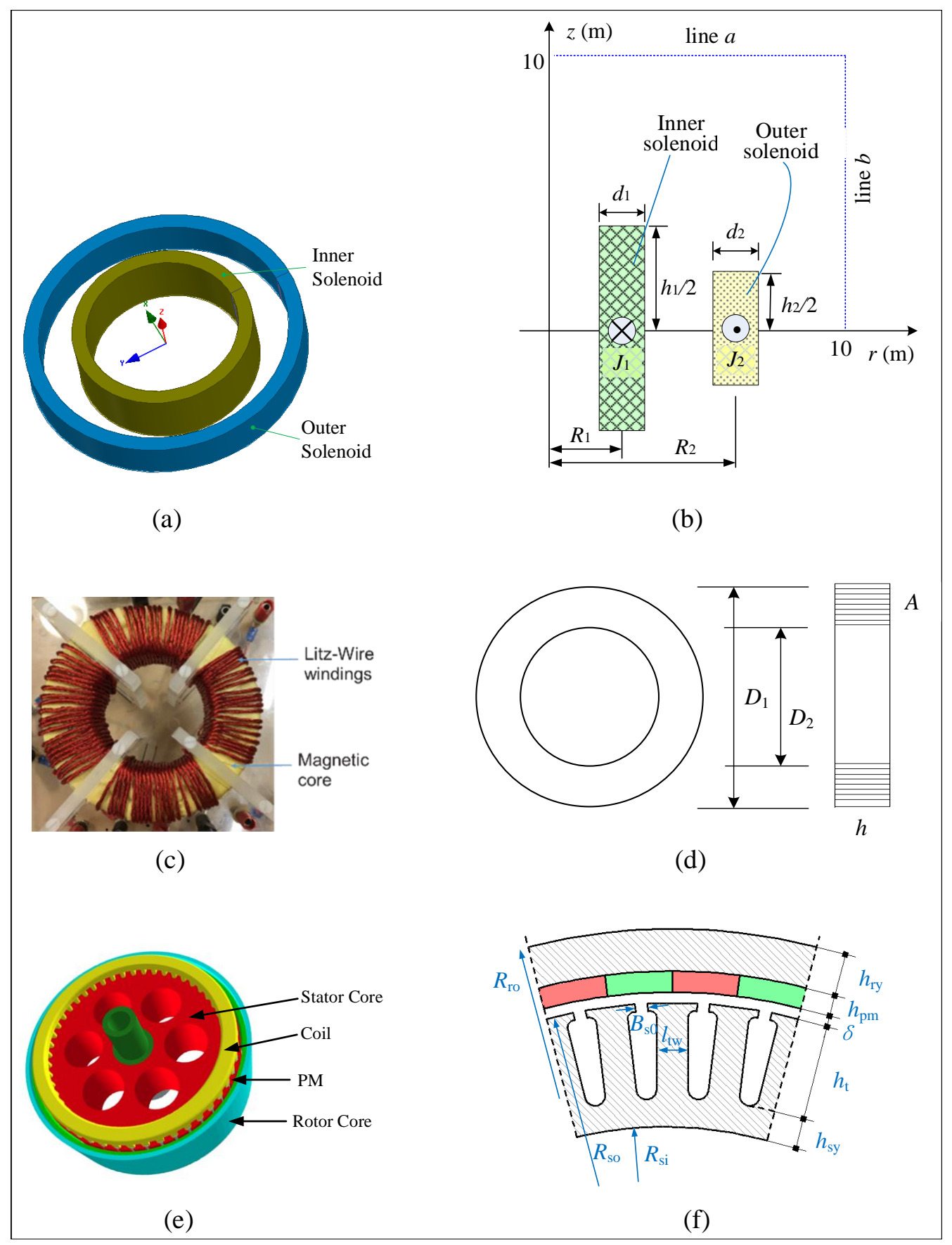

Figure 1. Design optimization illustrations of several electromagnetic devices, (a) a topology of superconducting magnetic energy storage (SMES) with two solenoids, (b) SMES design structure and optimization parameters, (c) a high-frequency transformer with Litz-wire windings, (d) design structure and optimization parameters for the high-frequency transformer, (e) a topology of an outer-rotor surface-mounted permanent magnet synchronous motor (SPMSM), (f) SPMSM design structure and optimization parameters. 
SMES is a grid-enabling device for power systems as it can store and discharge a large amount of electricity/power almost instantaneous. SMES stores the power in terms of magnetic energy by its superconducting coils. Nowadays, high penetration of renewable energy sources, like wind and solar, are integrated into the power system worldwide. They will affect the power quality and stability due to their intermittency. This is one of the main challenges of integrating renewable energy sources in the smart grid. SMES is a promising technology to address this challenge [19-21]. The common shapes of superconducting coils are solenoid (Figure 1a) or toroidal. The solenoid type is simple, robust, and cost-effective. For the design optimization of solenoid-type SMES, there are several parameters, such as the dimensions of the solenoids and currents.

Figure $1 \mathrm{~b}$ illustrates an optimization structure of an SMES based on a benchmark problem (TEAM problem 22) in ICS. For this example, eight parameters, $\mathbf{x}=\left[R_{1}, h_{1}, d_{1}, J_{1}\right.$, $\left.R_{2}, h_{2}, d_{2}, J_{2}\right]$, where $(R, h, d)$ and $J$ are the dimension and current density of the solenoid, respectively, subscript 1 and 2 mean the inner solenoid and outer solenoid, respectively. These parameters will be optimized to minimize the mean stray fields $\left(B_{\text {stray }}\right)$ while keeping the total stored energy $(E)$ close to $180 \mathrm{MJ}$. The optimization model can be defined as

$$
\begin{aligned}
\min : & \left\{\begin{array}{l}
f_{1}(\mathbf{x})=B_{\text {stray }} \\
f_{2}(\mathbf{x})=|E-180|
\end{array}\right. \\
\text { s.t. } & \left\{\begin{array}{l}
g_{1}(\mathbf{x})=\left|B_{\max }\right|-\min \left(\frac{54-\left|J_{i}\right|}{6.4}\right) \leq 0 \\
g_{2}(\mathbf{x})=R_{1}+\frac{d_{1}}{2}+\frac{d_{2}}{2}-R_{2}<0
\end{array}\right. \\
& \mathbf{x}_{l} \leq \mathbf{x} \leq \mathbf{x}_{u}
\end{aligned}
$$

In the model, $B_{\text {stray }}$ is estimated by the magnetic fields on 21 points with the same space along lines $a$ and $b$, as shown in Figure $1 \mathrm{~b}$. The first constraint is related to the superconductivity of the SMES, where the maximal magnetic field $\left(B_{\max }\right)$ is limited to a value determined by the current density of two coils. This optimization problem can be converted to a single-objective problem (minimizing the mean stray fields only) by considering the requirement of stored energy through a constraint [22-25].

Please note that there are no analytical expressions to show the relationship between design parameters and performance quantities of many electromagnetic devices, for example, the relationship between the parameters $\mathbf{x}$ and $E$ in (2). Thus, finite element analysis (FEA) method is widely employed to calculate the magnetic field distribution. For example, Figure 2 shows a design scheme of SMES and its magnetic field distribution by using FEA method (can be done in several software like ANSYS). Due to the symmetry, only the part above $\mathrm{x}$-axis is given. As shown, the maximal magnetic field (indicated as MX) is around 4.27 T. Other performance measures like the energy can be obtained based on the results for the magnetic field. If a parameter, like radius of the inner solenoid, is changed, the corresponding magnetic field and the values of $E, B_{\max }$, and $B_{\text {stray }}$ should vary as well. Thus, FEA and model link the design parameters and performance quantities.

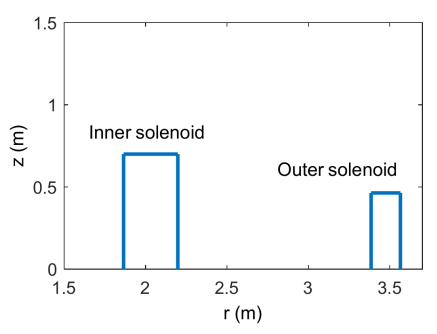

(a)

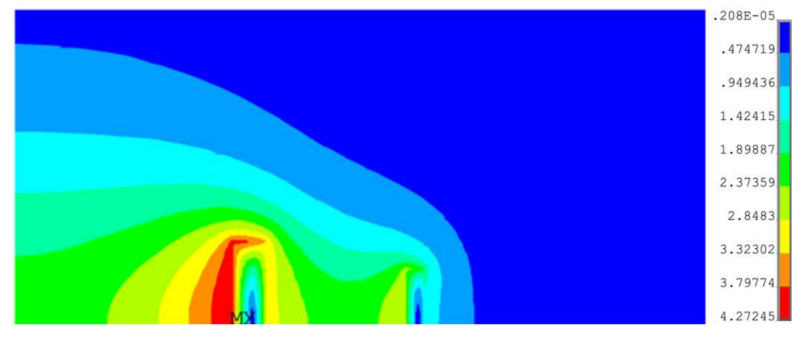

(b)

Figure 2. The magnetic field distribution for a design scheme of SMES with current density of $20 \mathrm{MA} / \mathrm{m}^{2}$, (a) the design scheme (symmetric about the $\mathrm{x}$-axis), and (b) the corresponding magnetic field obtained from ANSYS. 
Figure 1c shows a prototype of a high-frequency transformer with Litz-wire windings and a magnetic core made of nanocrystalline films. High-frequency transformers have many potential and promising applications, including in the power systems and wireless power transmission systems [26-28]. For the design optimization of a high-frequency transformer, there are many objectives, such as minimizing the loss and volume. Regarding the design optimization parameters, dimensions (as shown in Figure 1d) and core materials (like nanocrystalline or amorphous) can be considered [29-32]. Detailed optimization models can be referred to these works as well.

The third example is a PM motor. PM motors have been widely used in industry and transportation, such as hybrid electric vehicles [33-37]. The design optimization of electrical machines, including MP motors, is very challenging in many situations due to the consideration of multi-physics analysis. Figure 1e shows the topology of an outerrotor SPMSM. This kind of machine has been used in many applications as well, like in EVs. In our previous work, it is designed as an in-wheel motor for an EV to achieve fourwheel-drive performance [38,39]. This motor has many parameters to optimize, like the dimensions shown in Figure 1f. In addition, the material of PMs and winding parameters (like the number of turns and winding diameter) can be investigated. Popular optimization objectives are maximizing the output power, average torque, and efficiency, and minimizing the cost and torque ripple.

Furthermore, as this motor is used as the in-wheel motor, the operating condition should be considered. There are two major challenges for in-wheel-motors, the unsprung weight and cooling $[40,41]$. The unsprung mass is the weight of all components that are not supported by the suspension, including the wheels with motors, tires, and brakes. As the EV travels up and down over various bumps, potholes, and debris, excessive unsprung weight would cause serious vibration. The weight of in-wheel motors must be minimized (e.g., through topology optimization, will be discussed in Section 2.3.5) for smooth drive performance and better vehicle reliability and durability. Cooling is a critical issue for safe operation of high torque density in-wheel motors due to the limited and sealed space in the wheels. Therefore, accurate multi-physics analysis is required, including the electromagnetic, thermal, and mechanical analysis. Based on these considerations, an optimization model of this motor can be defined as

$$
\begin{array}{ll}
\min : & \left\{\begin{array}{l}
f_{1}(\mathbf{x})=-T_{\text {average }} \\
f_{2}(\mathbf{x})=T_{\text {ripple }} \\
f_{3}(\mathbf{x})=-\eta \\
f_{4}(\mathbf{x})=\text { Mass }
\end{array}\right. \\
\text { s.t. } \quad\left\{\begin{array}{l}
g_{1}(\mathbf{x})=\text { Tem }_{\text {pm }}-T_{0} \leq 0 \\
g_{2}(\mathbf{x})=\text { Tem }_{\text {coil }}-T_{1} \leq 0 \\
g_{3}(\mathbf{x})=\text { Vol }_{m}-V_{0} \leq 0
\end{array}\right. \\
\quad \mathbf{x}_{l} \leq \mathbf{x} \leq \mathbf{x}_{u}
\end{array}
$$

where $T_{\text {average }}, T_{\text {ripple }}, \eta$, and Mass represent the average torque, torque ripple, efficiency, and mass of the motor, respectively. The temperature rises in PM $\left(\operatorname{Tem}_{p m}\right)$, winding $\left(\operatorname{Tem}_{\text {coil }}\right)$, and motor volume $\left(\mathrm{Vol}_{m}\right)$ are considered as constraints. They should not be larger than the limits (indicated as $T_{0}, T_{1}$, and $V_{0}$ ). For example, for a specific type of PM N38M, its Curie temperature is $100^{\circ} \mathrm{C}$. To avoid demagnetization in operation, $T_{0}$ can be defined as $70^{\circ} \mathrm{C}$, assuming that the room temperature in an application is $30^{\circ} \mathrm{C}$. In the implementation of the optimization, both magnetic field analysis and thermal analysis should be conducted first to estimate parameters in (3), except the Mass and Volume. Then an optimization algorithm/method can be applied to find the optimal parameters $\mathbf{x}$. Similarly, it is hard to analytically express the relationship between parameters $\mathbf{x}$ and many performance quantities in (3), such as torque ripple and efficiency. Therefore, FEA is required for this motor (applies to other motors as well). 


\subsection{Design Optimization Models in The Presence of Uncertainties}

Theoretically, the performance of an electromagnetic device can be improved by optimizing the optimization model of (1) or its single-objective form. However, this kind of optimal design (mathematical optimum) often features a lower performance than expected after the practical manufacturing process, because there are many inevitable material diversities and uncertainties involved. For example, assume that the optimal height of PMs is $4 \mathrm{~mm}$ for an SPMSM after an optimization. Considering a batch production of this motor (for examples, 1000 motors) with this design scheme, the practical height should be around $4 \mathrm{~mm}$, like $4.05 \mathrm{~mm}$ and $3.97 \mathrm{~mm}$, after measurement. It normally follows a normal distribution, as indicated by some research work [15]. Therefore, the practical performance of this motor will be different from the theoretically optimized value. There are obvious variations in batch production. To improve the manufacturing quality of the motors and other electromagnetic devices, some quality control methods, like six-sigma quality control, can be applied. However, this requires a lot of resources which may be a burden for some companies. Alternatively, this problem can be investigated in the early stage of product development through robust design optimization [6,14,42-46].

Figure 3 illustrates a comparison of deterministic and robust optimums, and their performance variations in the presence of uncertainties. As shown, there are two optima, indicated as deterministic and robust optimum. For rated conditions, the deterministic one is better than the robust one. However, when a variation $\Delta x$ occurs, the performance of the deterministic design shows a significant degradation, while some designs likely will not fulfill the illustrated constraint regarding the maximum objective value. This will be regarded as a defect in practical quality evaluation. For example, considering the design optimization of a PM motor, the temperature rise in the winding shall be less than $70^{\circ} \mathrm{C}$. Then, normally, the deterministic design will have an optimum with a temperature rise of the exact $70^{\circ} \mathrm{C}$ or very close to it, like, e.g., $69.7^{\circ} \mathrm{C}$. If any uncertainties happen during the manufacturing or operation, the practical temperature rise in the PM may exceed this limit. This may demagnetize the PMs and fail/damage the whole device. By contrast, the robust optimum can ensure the required quality of the device in batch production $[6,47]$. That is why the popularity of robust design optimization is increasing compared to the conventional deterministic design optimization in many research fields, including the design optimization of electromagnetic devices.

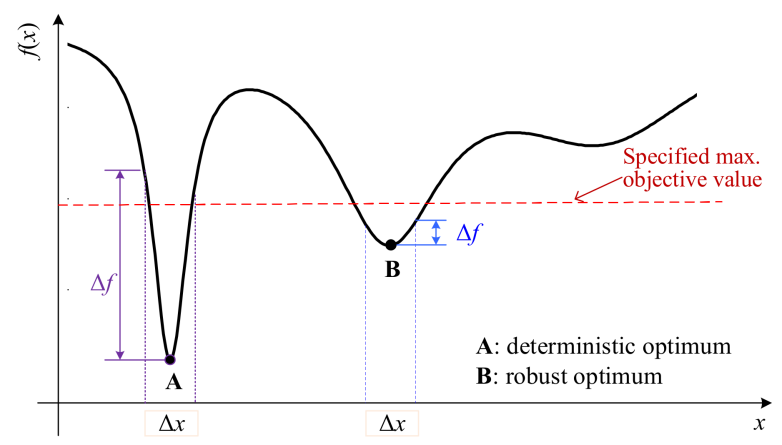

Figure 3. A comparison between the deterministic optimum and robust optimum in the presence of uncertainties for a function $f(x)$, in which $\Delta x$ and $\Delta f$ stand for the variations of the parameter and objective, respectively.

There are three popular approaches for the robust design optimization of electromagnetic devices, namely Taguchi parameter design, worst-case design, and design for six-sigma (DFSS) [47-54]. Figure 4 shows a block diagram for the Taguchi parameter design method. In this method, the parameters are classified as two groups, control factors and noise factors. Some techniques, such as orthogonal array and signal-to-noise ratios, are then employed to determine the best combination of control factor levels so that the variation of this response is minimized in the presence of noise factors [54]. The Taguchi 
parameter design has been widely employed in many applications due to its efficiency and effectiveness. However, there are several drawbacks, e.g., it cannot effectively deal with the constraints in optimization models.

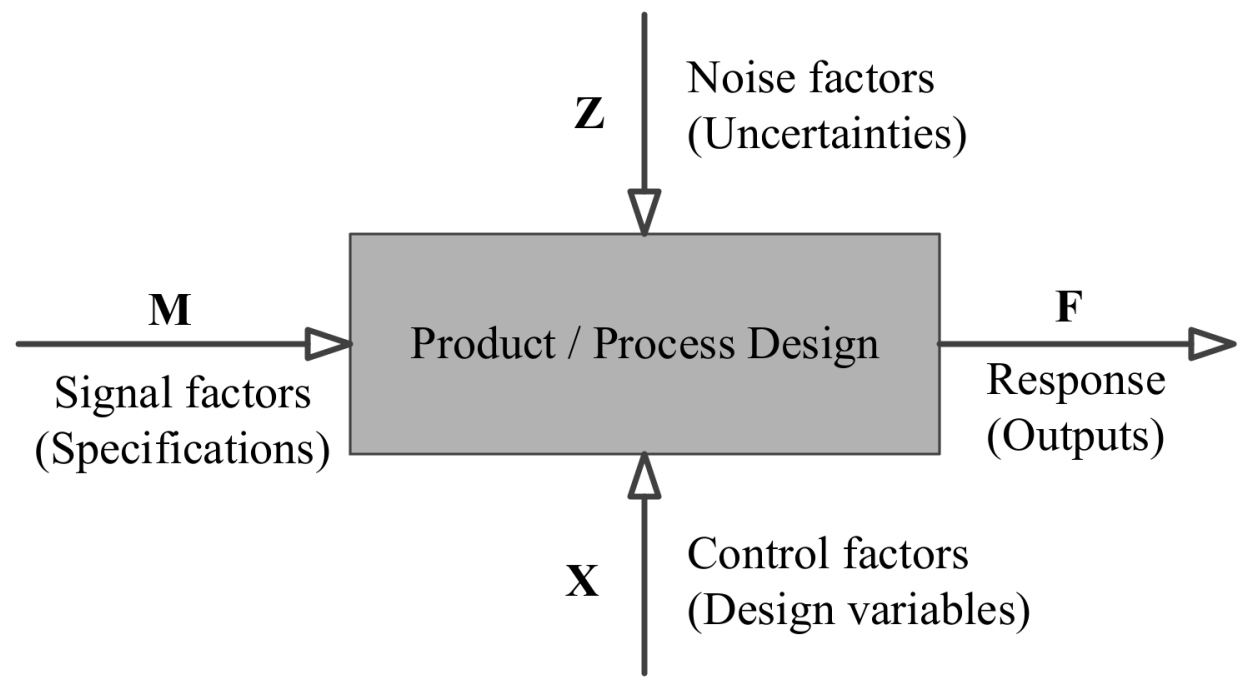

Figure 4. Block diagram of a product/process design in Taguchi method considering control factors (design variables) and noise factors (uncertainties).

Worst-case design and DFSS are able to handle both constraints and optimization objectives in a generic optimization model. Regarding the worst-case approach, its multiobjective optimization model can be defined as

$$
\begin{array}{cl}
\min : & \left\{f_{w, i}(\mathbf{x})=\max _{\xi \in U(\xi)} f_{i}(\mathbf{x}, \xi), i=1,2 \ldots, p\right\} \\
\text { s.t. } & g_{w, j}(\mathbf{x})=\max _{\xi \in U(\xi)} g_{j}(\mathbf{x}, \xi) \leq 0, j=1,2, \ldots, m \\
& U(\xi)=\left\{\xi \in \mathbb{R}^{k}|| \xi-\xi_{n} \mid \leq \Delta \xi\right\}
\end{array}
$$

where $\xi$ and $\xi_{n}$ are vectors representing the actual and nominal values of noise factors, respectively, and $U(\xi)$ represents the uncertainty range of these parameters, $\Delta \xi$ is a vector for the limit of uncertainty range, $\mathbb{R}$ stands for real coordinate space, $k$ is dimension, subscript $w$ in the objective, and constraints means the worst case.

For the DFSS approach, its multi-objective optimization model can have the form as

$$
\begin{array}{cl}
\min : & \left\{F_{i}\left[\mu_{f}(\mathbf{x}), \sigma_{f}(\mathbf{x})\right], i=1,2, \ldots, p\right\} \\
\text { s.t. } & g_{j}\left[\mu_{f}(\mathbf{x}), \sigma_{f}(\mathbf{x})\right] \leq 0, j=1,2, \ldots, m \\
& \mathbf{x}_{l}+n \sigma_{\mathbf{x}} \leq \mu_{\mathbf{x}} \leq \mathbf{x}_{u}-n \sigma_{\mathbf{x}} \\
& \mathrm{LSL} \leq \mu_{f} \pm n \sigma_{f} \leq \mathrm{USL}
\end{array}
$$

where $\mu$ and $\sigma$ are the mean and standard deviation, respectively, $\mu_{\mathbf{x}}$ and $\sigma_{\mathbf{x}}$ are the mean and standard deviation, respectively, are the mean and standard deviation of $\mathbf{x}$, respectively, LSL and USL are the lower and upper specification limits, respectively. $n$ is the sigma level, and it is defined as 6 in many applications. The value of $n$ can be equivalent to a probability of a normal distribution, as shown in Figure 5. Six-sigma level $(n=6)$ has been widely adopted in industry as it can provide good reliability for both short-term quality control (equivalent to statistic values) and long-term quality control (with considerations of uncertainties by shifting mean with $1.5 \mathrm{\sigma}$ ). It is equivalent to 0.002 (or a per cent of pass $99.9999998 \%$ ) for short-term quality control and 3.4 defects per million opportunities (DPMO) for long-term quality control $[6,14,48]$. 


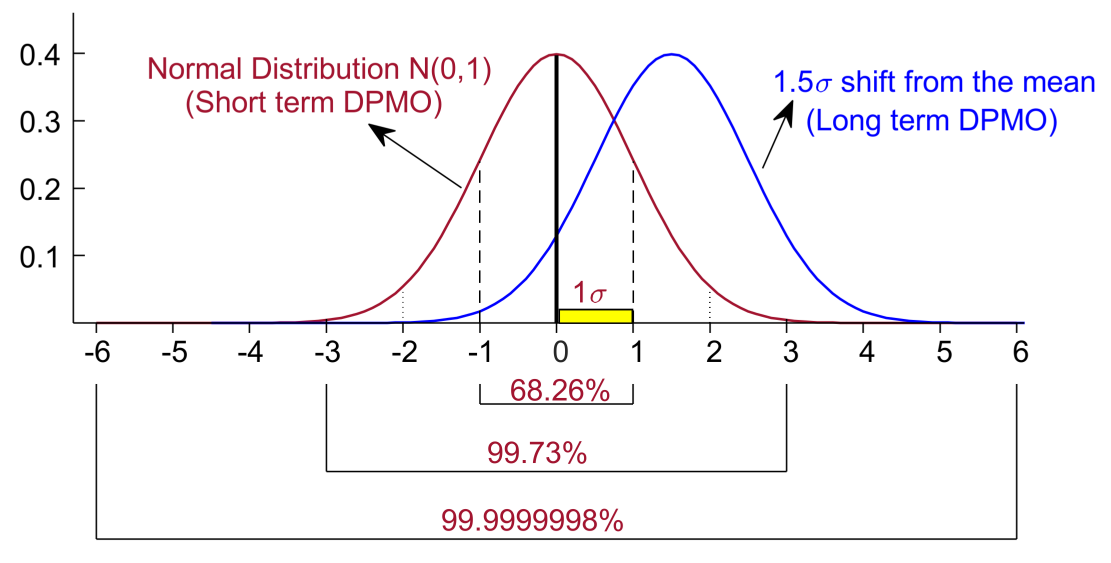

Figure 5. Probability density function of the standard normal distribution for short-term quality control and long-term quality control (with a $1.5 \sigma$ shift from the mean), with probabilities for three sigma levels.

As an example, the robust optimization model of the investigated SMES with deterministic optimization model (2) can be defined as

$$
\begin{aligned}
\min : & \left\{\begin{array}{l}
f_{1}(\mathbf{x})=\mu\left(B_{\text {stray }}\right)+\sigma\left(B_{\text {stray }}\right) \\
f_{2}(\mathbf{x})=\mu(|E-180|)+\sigma(|E-180|)
\end{array}\right. \\
\text { s.t. } & \left\{\begin{array}{l}
g_{1}(\mathbf{x})=\mu\left(\left|B_{\text {max }}\right|-\min \left(\frac{54-\left|J_{i}\right|}{6.4}\right)\right)+6 \sigma\left(\left|B_{\text {max }}\right|-\min \left(\frac{54-\left|J_{i}\right|}{6.4}\right)\right) \leq 0 \\
g_{2}(\mathbf{x})=\mu\left(R_{1}+\frac{d_{1}}{2}+\frac{d_{2}}{2}-R_{2}\right)+6 \sigma\left(R_{1}+\frac{d_{1}}{2}+\frac{d_{2}}{2}-R_{2}\right)<0
\end{array}\right. \\
& \mathbf{x}_{l}+6 \sigma_{\mathbf{x}} \leq \mu_{\mathbf{x}} \leq \mathbf{x}_{u}-6 \sigma_{\mathbf{x}}
\end{aligned}
$$

where $\mu$ and $\sigma$ are the mean and standard deviation, respectively. In the implementation, each design optimization in $\mathbf{x}$, like $R_{1}$ (radius of the inner solenoid) can be assumed to follow a normal distribution with two parameters, a mean (the nominal value of a design) and a standard deviation (one third of its manufacturing tolerance) $[6,14]$.

In the implementation of the robust optimization, the evaluation processes of nominal performance quantities, like $E, B_{\max }$, and $B_{\text {stray }}$ are same as those applied for solving (2), like FEA. The main difference between (2) and (6) is that some extra information $(\mu$ and $\sigma$ ) is needed in (6). To obtain the required data sets, Monte Carlo method can be applied with four main steps. First, assume that each parameter in $\mathbf{x}$ follows a normal distribution. Second, generate a large amount of samples, like 10,000 samples (means 10,000 design schemes of SMES), from the distributions. Third, evaluate the SMES's performance quantities, such as $E$ and $B_{\max }$, for these 10,000 designs. Fourth, estimate the mean and standard deviation of these performance quantities. Then optimization algorithms can be applied to find the optimum solutions for this model.

There are two main differences between the worst-case approach and DFSS approach. First, the worst-case multi-objective model is a minimax optimization problem. It uses the worst motor performance of a design under uncertainties as a measure of robustness. DFSS uses the sigma level as the measure of robustness. Second, the probability distribution functions of the uncertainty parameters are required for DFSS, while the worst-case approach only needs intervals for the uncertain parameters. In general, the computation cost of worst-case is higher than that of DFSS, as it is a minimax optimization problem. Moreover, the worst-case approach is typically more affected by modeling errors, as this quantity is estimated based on a single numerical result, while DFSS measures are determined by evaluating a significant number of design variations.

In the case of hybrid uncertainties, the objective functions and constraints have the characteristics of both random and interval uncertainties. Both worst-case and DFSS should 
be considered in the optimization model, and the computation cost is huge. This kind of robust optimization has been investigated for a PM motor in our previous work. Polynomial chaos Chebyshev interval (PCCI) method was employed to improve its optimization efficiency [49]. In the context of Industry 4.0, robust design optimization has been an active and promising research topic in many fields recently, including electrical engineering, mechanical engineering, and civil engineering. A main driving force behind this is that robust design optimization is able to include the manufacturing data and product quality into the design problem. There are many research activities about the robust design analysis and optimization of different types of electromagnetic devices, such as SMES [21,50-53], and several types of electrical machines including high-temperature superconducting linear synchronous motor [55], and synchronous reluctance motors [56], and PM motors [57-65]. It is observed that there are more discussions on robust design optimization of PM motors than other types of electrical machines, due to the fact that there are many uncertainties for the PMs. These uncertainties will affect the performance of the PM motors and their reliability, e.g., considering potential demagnetization. This is also challenging for the mass-production of the PM motors. Recently, a special section on robust design and analysis of electric machines and drives was published in the IEEE Transactions on Energy Conversion. Both the robust design analysis and optimization of the motors and control systems are investigated by many authors and, correspondingly, a significant number of papers was published [66]. The outcomes will lay a solid foundation for the development of high-reliability electrical drive systems for many challenging applications, such as EVs and wind power generation.

\subsection{Optimization Methods}

\subsubsection{Optimization Algorithms}

After the development of single- and/or multi-objective optimization models, different optimization methods can be employed to discover the optimal results. In general, optimization methods consist of optimization algorithms and strategies. Regarding the optimization algorithms, there are many types, such as gradient-based algorithms and evolutionary optimization algorithms (called intelligent optimization algorithms in many situations). Due to the nature of the high nonlinearity of the optimization models, evolutionary optimization algorithms are more popular nowadays, such as genetic algorithm (GA), differential evolution algorithms (DEAs), particle swarm optimization (PSO) algorithms, grey wolf algorithm, objective black hole algorithm, and their improvements [39,67-92]. More details about these optimization algorithms with applications to different electromagnetic devices can be found in review papers $[4,5,14]$.

\subsubsection{Surrogate Models or Approximation Models}

A major challenge for optimizing models (1)-(6) or their single-objectives forms with an appropriate algorithm is the large computation cost, as accurate magnetic field distribution obtained from 2-D or 3-D FEA is required for many applications, like PM motors. The FEA usually takes a lot of simulation time, especially for some complex electromagnetic devices that require 3-D finite element models (FEMs). Therefore, surrogate models, such as response surface model (RSM), radial basis function model (RBF), and Kriging model, have been employed to approximate the performance of electromagnetic devices, like flux linkage and core loss. These models can be developed based on the simulation data of FEM by using an appropriate design of experiment (DoE) technique [93-96]. Details about surrogate models and their applications to different electromagnetic devices can, for instance, be found in $[4,5,14]$. A comparison of different surrogate models will be discussed in Section 3.1, with consideration of several machine learning models. Furthermore, these surrogate models can be used to estimate the mean and standard deviation terms in the robust optimization. This will significantly reduce the computation cost of the typical Monte Carlo analysis with finite element model. 


\subsubsection{Multilevel and Space Reduction Optimization Strategies}

Surrogate models can be used to improve the optimization efficiency or reduce the computation cost of low-dimensional electromagnetic design problems, for example, in case a total of five dimensions is not exceeded. Its efficiency is not good for high-dimensional optimization problems, such as the optimization of SMES with 8 parameters (Figure 1b) and the optimization of a PM motor with 10 parameters and FEM (Figure 1f). Therefore, appropriate optimization strategies should be considered. For this purpose, three optimization strategies, namely multilevel optimization, space reduction optimization, and sequential optimization strategies have been proposed in our previous work for both deterministic/robust and singleor multi-objective optimization problems of electromagnetic devices $[6,14,47,97-100]$.

For the multilevel optimization strategy, a high-dimensional optimization problem is converted into several low-dimensional optimization problems by using sensitivity analysis techniques, such as local sensitivity and analysis of variance. Considering the optimization of SMES with 8 parameters, a three-level structure can be defined as: Level 1 (3 parameters of $\left.\left[R_{1}, h_{1}, d_{1}\right]\right)$, Level 2 (2 parameters of $\left[J_{1}, J_{2}\right]$ ), or Level 3 (3 parameters of $\left[R_{2}\right.$, $\left.\left.h_{2}, d_{2}\right]\right)$. To implement the optimization, a sequential optimization process, Level 1-Level 2-Level 3, will be conducted, as shown in Figure 6. This process should be repeated until a convergence criterion is met (for example, the relative error of the objectives between two iterations are no more than a given value $\varepsilon$ like $1 \%$ ). This kind of optimization strategy will decrease the computation cost, as the optimization of each level is a low-dimensional problem which can be done effectively by a surrogate model. For example, if each factor needs 5 levels in a DoE technique, then Level 1 requires 125 points, Level 2 requires 25 points, and Level 3 requires 125 FEM points, resulting in a total of 275 points for one loop of the optimization. If three optimization loops are needed, a total of 825 points are required for multilevel optimization. This is much smaller than the samples $(125 \times 125 \times 25=390,625)$ required by developing a model for 8 input parameters.

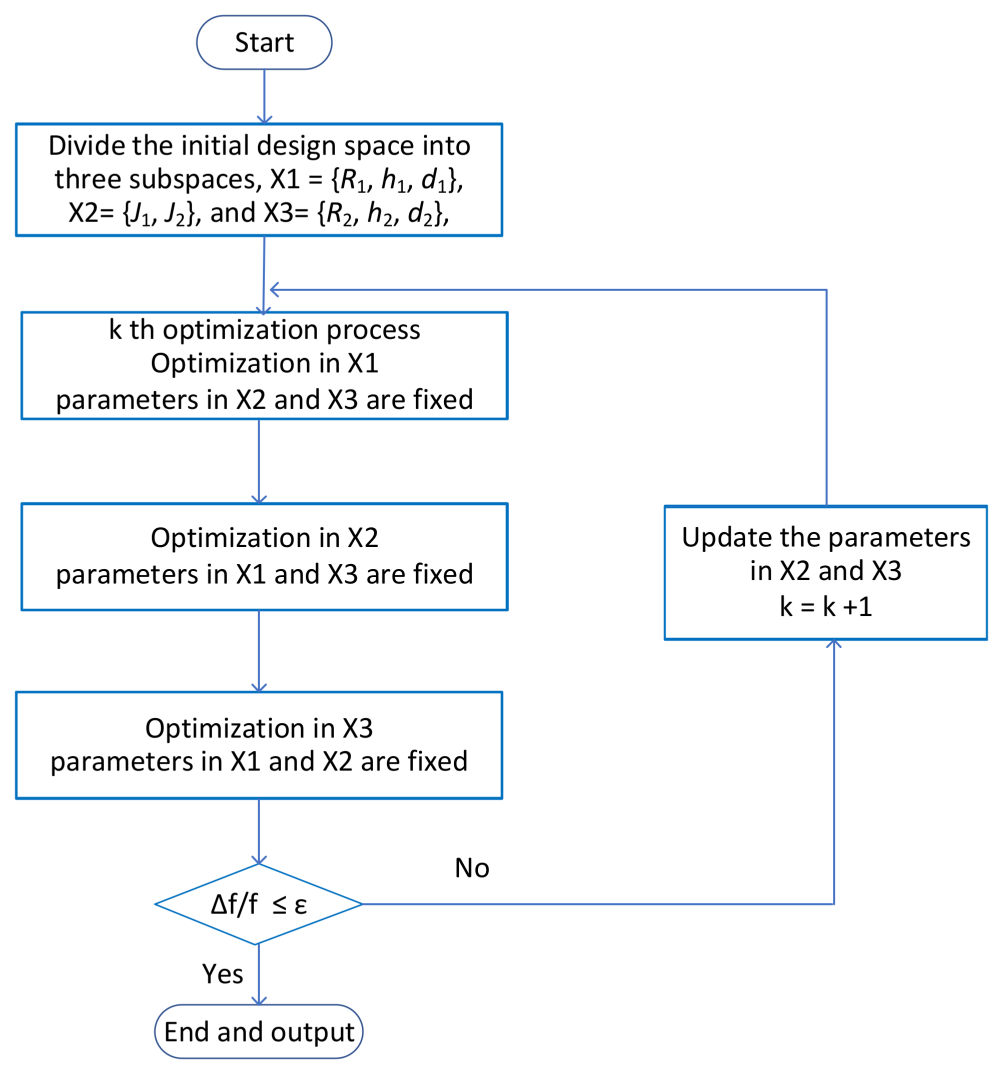

Figure 6. A three-level optimization flowchart for SEMS, in which 8 optimization parameters are allocated to three subspaces X1, X2, and X3. 
For the sequential optimization strategy, it uses a sophisticated strategy to sample the most important variants in a small subspace (instead of the initial big design space) by using some space reduction and moving techniques. According to the design examples on SMES and PM motors with soft magnetic composite cores, it can be found that the computation cost of FEA has been reduced significantly by using these strategies. These and improved optimization strategies (like new and improved sensitivity analysis methods) have been successfully applied to the design optimization of other PM motors [35,38,101].

\subsubsection{System-Level Multidisciplinary Design Optimization}

Besides the optimization problems discussed above, there are two emerging and challenging research topics in the design optimization of electromagnetic devices, systemlevel design optimization and topology optimization.

The system-level design optimization is very important for electrical machines and drive systems, e.g., the in-wheel motor drive systems for EVs. The conventional componentlevel (e.g., the motor) optimization cannot guarantee optimal performance of the whole system. To design and optimize this kind of drive systems, electromagnetic analysis, thermal analysis, mechanical analysis, power electronics, and control systems have to be investigated in the optimization [102-110]. Therefore, multidisciplinary design optimization methods should be investigated. Another example is the design of high-speed electrical machines, where utilizing a multi-physics analysis is crucial to obtain accurate and good optimization results $[8,9,111]$.

\subsubsection{Topology Optimization}

The optimization discussed above is mainly about the structure size or dimension optimization of the electromagnetic devices, which is one of the three main optimizations in engineering, structural size, shape, and topology optimizations. The topology optimization aims to obtain the optimal layout of components in the design domain for the best objective performance. Compared with the former two optimization methods, the topology optimization is more adept at innovative concept design with superior performance. Moreover, it can shorten the design cycle with less expertise to the optimal design [112]. Topology optimization has been an important research topic in computational electromagnetics for a significant time. It has attracted much attention nowadays due to the requirements of some modern electromagnetic devices, like the in-wheel motor drive systems for (hybrid) EVs, and the development of some advanced AI techniques like deep learning (this will be discussed in the next section) [113-116]. As mentioned in Section 2, unsprung weight is a major challenge for in-wheel-motors $[40,41]$. The weight of in-wheel motors must be minimized for smooth driving performance and better vehicle reliability and durability. Topology optimization is an effective method to achieve this goal. In many situations, some holes can be designed to the ferromagnetic cores of the motors, such as the stator cores of SPMSMs (Figure 1ef) [112].

There are some challenges for topology optimization as well. To ensure good manufacturability of the obtained design, some constraints, like rounded corners, should be considered in the optimization. Alternatively, this aim can be achieved by robust topology optimization (a combination of robust optimization and topology optimization).

\subsubsection{Fuzzy Optimization}

The optimization effectiveness of deterministic and robust models depends on the precise quantifications of design parameters and uncertainties. However, these quantifications are not always possible. Fuzzy optimization is good at handling this kind of uncertainty. In this case, the performance of electromagnetic devices can be described as qualitative objectives, such as high, medium, and low. Fuzzy membership functions can be used to quantify them and can be included in quantitative optimization models. There are two main types of fuzzy optimization problems in terms of the consideration of constraints. Fuzzy programming has been developed and widely used to handle optimization problems 
with fuzzy parameters and constraints $[117,118]$. Fuzzy optimization has been employed to design electromagnetic devices, including different types of motors [119-121]. In addition, fuzzy method has been combined with Taguchi method to address multi-objective optimization of electromagnetic devices [122-128]. Taguchi method has a drawback of handling robust multi-objective optimization of electromagnetic devices. Fuzzy method can be employed to solve this kind of problem.

\section{Machine Learning for the Design Optimization of Electromagnetic Devices}

From the review and discussions in Section 2, it can be seen that there are two major challenges in the design optimization of electromagnetic devices. First, accurate multiphysics analysis is required for many applications, but it normally requires huge computation cost of FEA, for example, for the design of high-speed PM motors. Second, highly-accurate surrogate models are essential for the optimization process. Naturally, the surrogate models of electromagnetic devices are highly nonlinear. In this case, nonparametric models may be superior to the parametric and semi-parametric models for the performance prediction as there is no specific relationship (like linear) between the inputs and outputs. For example, the relationship between efficiency of a PM motor and its dimension may not be able to predict accurately by using polynomials (or RSMs). Fortunately, machine learning presents an opportunity to address these two challenges.

Machine learning is a method of data analysis (including prediction and optimization) that automates analytical model building. It is seen as a subset of artificial intelligence. As a type of non-parametric modeling technique, machine learning is good at developing complex nonlinear relationships between a number of inputs and outputs by using different neural networks. Thus, it can be used to build surrogate models for models (1)-(6). Many machine learning algorithms have been used to the design optimization of electromagnetic devices, such as artificial neural networks (ANN), support vector machines (SVM), extreme learning machines (ELM), random forest (RF), and deep learning (DL) [3]. DL is a kind of deep neural network (DNN), and is one subset of machine learning algorithms. There are many more layers of neurons in the architectures of DL, compared with ANN, which can be employed to achieve specialized functionalities. To apply them to design electromagnetic devices, there are two major contributions in the common practice. First, these algorithms have been used to predict/estimate the device's field distribution or performance. Second, they can be used to develop surrogate models for optimization [129-153].

Table 1 lists a comparison of several surrogate models for performance prediction and optimization of electromagnetic devices. There are three types regarding their parametrization. The first category is about parametric models. It includes RSM and RBF. The second one gives semi-parametric models, e.g., Kriging based approaches. The last group involves non-parametric models. It includes three popular machine learning models with explicit mathematical expressions, i.e., ANN, SVM, and ELM. Please note that RF and DL models are not included in this table as they are hard to be expressed by explicit mathematical equations.

These models have been employed to design and optimize different types of electromagnetic devices recently. Please note that different networks may be applied to these machine learning models. For example, there are two popular networks of ANN, backpropagation (BP) and radial basis function networks. Additionally, there are many types of $\mathrm{DL}$, such as the convolutional neural network $(\mathrm{CNN})$, recurrent neural network (RNN), and generative adversarial networks (GAN). Table 2 lists some selective bibliography focusing on electromagnetic device design optimization based on different machine learning methods. More details are discussed in the following subsections.

\subsection{Machine Learning for Performance Prediction of Electromagnetic Devices}

The performance of electromagnetic devices highly depends on the field analysis results of electromagnetic, mechanical, and thermal analyses. These analyses are usually based on FEA and time-consuming, as different dimension and materials and excitations will affect the results. Moreover, the performance of electromagnetic devices, like the torque 
and efficiency of a motor, depends on the accurate estimation of the flux linkage and core loss. Typically, those measures feature strongly nonlinear and multi-modal characteristics regarding the input parameters, e.g., due to saturation effects. Consequently, surrogate models based on parametric or semi-parametric approaches might not follow accurate results in general. Through several attempts on machine learning methods, it is found that deep learning algorithms, like CNN and RNN, are good at the distribution estimation of magnetic field and temperature [129-131], and the prediction of torque and efficiency for motors [132-134]. These works established a solid foundation for the generalizable datadriven model for the analysis, design, and optimization of electromagnetic devices [129].

Table 1. Comparison of several surrogate models.

\begin{tabular}{|c|c|c|}
\hline Model & Mathematical Expression & Type \\
\hline Response surface model (RSM) & $\begin{array}{c}y=X \beta+\varepsilon \\
X: \text { Structure matrix; } \beta \text { : Coefficient matrix }\end{array}$ & Parametric \\
\hline Radial basis function (RBF) & $y=\sum_{i=1}^{n} \beta_{i} H\left(\left\|\mathbf{x}-\mathbf{x}_{i}\right\|\right)$ & Parametric \\
\hline Kriging & $\begin{array}{c}\text { H: RBF function; } \beta_{i} \text { : Coefficient matrix } \\
y=q(\mathbf{x})^{\prime} \beta+z(\mathbf{x}) \\
q(\mathrm{x}) \text { : Basis function; } \beta \text { : Coefficient matrix; } \mathrm{z}(\mathrm{x}) \text { : A stochastic } \\
\text { process }\end{array}$ & Semi-parametric \\
\hline Artificial neural networks (ANN) & $\begin{array}{l}\qquad y_{j}=f\left(\sum_{i=1}^{n} w_{j i} x_{i}-\theta_{j}\right) \\
\text { Basic artificial neuron model, } w_{j i} \text { : Weightings, } \theta_{j} \text { : Neuron's } \\
\text { activation threshold; } f \text { : Transfer function. }\end{array}$ & Non-parametric \\
\hline Support vector machines (SVM) & $\begin{array}{l}y=w \cdot \phi(x)+b \\
\phi: \text { A function maps the input space to a higher dimensional } \\
\text { feature space, } w \text { is a weighting vector, } b \text { : Bias term. }\end{array}$ & Non-parametric \\
\hline Extreme learning machines (ELM) & $\begin{array}{c}\qquad y=\sum_{i=1}^{K} \beta_{i g}\left(\mathbf{w}_{i} \mathbf{x}_{j}+b_{i}\right) \\
g: \text { Activation function, w: Weighting vector; } \mathbf{b} \text { : Threshold } \\
\text { [138]. }\end{array}$ & Non-parametric \\
\hline
\end{tabular}

An example for the torque prediction of a switched reluctance motor (SRM) based on SVM is considered in the following. Figure 7 shows the machine topology of a segmentedrotor SRM with 16/10 stator/rotor poles. As shown, the motor consists of 8 excited stator poles and 8 auxiliary poles (16 poles in total). The basic operating principle and structural parameters of this motor have been introduced in our previous work [133]. In general, accurate torque modeling of SRM is a difficult problem, as this motor features a double salient structure. Thus, the torque response usually shows a significant ripple, and its modeling is a highly nonlinear problem. In a previous study, two significant factors, phase current and position angle, were investigated as inputs for modeling the torque based on three forms of SVM algorithms. They are a conventional SVM, a least square support vector regression (LSSVR), and a maximum-correntropy-criterion-based least squares support vector regression (MCC-LSSVR). Figure 8 illustrates the modeling of phase flux linkage and torque of this motor by using the MCC-LSSVR model. Table 3 lists the mean absolute error (MAE) and root mean square error (RMSE) for all three modeling approaches. As shown, the MCC-LSSVR model appears more effective than the other two techniques. 
Table 2. Selective bibliography focusing on electromagnetic device design optimization based on different machine learning methods.

\begin{tabular}{|c|c|c|c|}
\hline Reference & Model & Application & $\begin{array}{l}\text { Estimation Objectives or } \\
\text { Optimization Methods }\end{array}$ \\
\hline [129] & $\begin{array}{l}\text { Convolutional neural } \\
\text { network (CNN) }\end{array}$ & $\begin{array}{l}\text { Electromagnetic devices including } \\
\text { transformer and permanent magnet } \\
\text { (PM) motor }\end{array}$ & Magnetic field estimation \\
\hline$[130,131]$ & $\begin{array}{l}\mathrm{CNN} \text {, recurrent neural } \\
\text { network }(\mathrm{RNN})\end{array}$ & $\begin{array}{l}\text { permanent magnet synchronous } \\
\text { motor (PMSMs) }\end{array}$ & Temperature Estimation \\
\hline [132] & ANN, CNN, RNN & Interior PM motors & $\begin{array}{l}\text { Efficiency map and } \\
\text { flux-linkage prediction }\end{array}$ \\
\hline$[133,134]$ & SVM & Switched reluctance motor & Torque prediction \\
\hline$[135,136]$ & SVM & PMSMs & Multi-objective optimization \\
\hline [137] & Random forest (RF) & Induction machine & Random forest algorithms \\
\hline [138] & ELM & PM synchronous linear motors & $\begin{array}{l}\text { Multi-objective optimization, grey } \\
\text { wolf optimization algorithm }\end{array}$ \\
\hline [139] & K-nearest neighbor (KNN) & PM synchronous linear motors & Differential evolution algorithm \\
\hline [140] & Multi-layer perceptron (MLP) & PMSMs & Hybrid metaheuristic algorithm \\
\hline [141] & $\begin{array}{l}\text { R-DNN (deep } \\
\text { neural network) }\end{array}$ & Double secondary linear motor & Cuckoo search algorithm \\
\hline [142] & $\mathrm{CNN}$ & Synchronous reluctance motor & $\begin{array}{c}\text { Binary particle swarm } \\
\text { optimization algorithm }\end{array}$ \\
\hline [143-145] & $\mathrm{CNN}$ & Interior PM motors & $\begin{array}{l}\text { Topology optimization, } \\
\text { multi-objective optimization, } \\
\text { genetic algorithm }\end{array}$ \\
\hline [146] & ANN & High-frequency transformer & Structure optimization \\
\hline [147-150] & ANN, SVM, DNN & Antennas & $\begin{array}{l}\text { Multi-objective and robust } \\
\text { design optimization }\end{array}$ \\
\hline
\end{tabular}

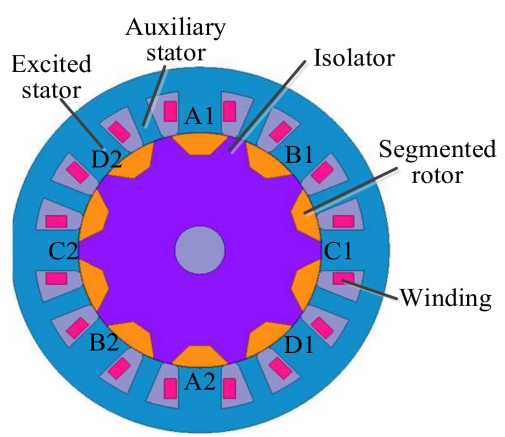

Figure 7. Machine topology of the 16/10 SRM with segmented rotors and excited and auxiliary stators.

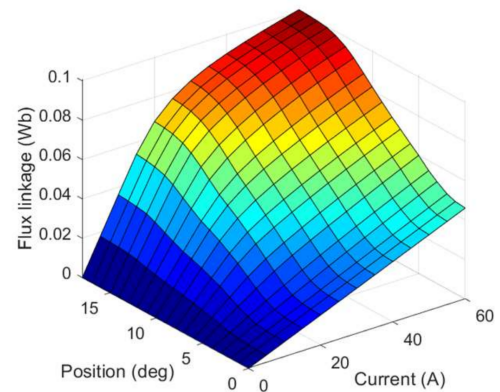

(a)

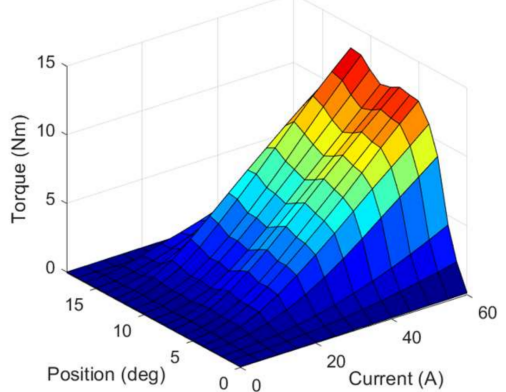

(b)

Figure 8. (a) Flux linkage prediction based on MCC-LSSVR model with respect to phase current and position angle, (b) torque prediction based on MCC-LSSVR model with respect to phase current and position angle. 
Table 3. Comparison of modeling accuracy of several methods.

\begin{tabular}{ccccc}
\hline \multirow{2}{*}{ Modeling Method } & \multicolumn{2}{c}{ Flux Linkage $(\mathbf{m W b})$} & \multicolumn{2}{c}{ Torque (Nm) } \\
& MAE & RMSE & MAE & RMSE \\
\hline SVM & 0.846 & 0.756 & 0.1008 & 0.0925 \\
LSSVR & 0.424 & 0.306 & 0.0525 & 0.0494 \\
MCC-LSSVR & 0.086 & 0.073 & 0.0252 & 0.0189 \\
\hline
\end{tabular}

\subsection{Machine Learning for Optimization of Electromagnetic Devices}

Overall, there is more research carried out on machine learning for improving the runtime of the optimization of electromagnetic devices, as was also shown in Table 2. Different machine learning algorithms, such as SVM, multi-layer perceptron (MLP), Knearest neighbor (KNN), and CNN have been investigated to optimize transformers, antennas, and motors (motors are the majority applications) [135-142,146-150]. It is noted that deep learning follows promising results when applied for topology optimization of electromagnetic devices, and this topic has attracted much attention recently [143-145]. The presented studies confirmed that good optimization results can be obtained by using different machine learning models for optimization.

To illustrate the effectiveness of these models, as an example, a single-objective optimization problem of a SMES is investigated below. Three types of surrogate models, RBF (a parametric model), Kriging (a semi-parametric model), and ANN (a non-parametric model), are compared. Meanwhile, an optimization strategy, sequential optimization method (SOM), is investigated to decrease the computation cost of FEM.

In the optimization, the dimensions of the outer superconducting coil, $\left[R_{2}, h_{2} / 2, d_{2}\right]$ as shown in Figure $1 \mathrm{~b}$, are optimized to minimize the mean stray fields $\left(B_{\text {stray }}\right)$ while keeping the stored energy $(E)$ close to $180 \mathrm{MJ}$ and guaranteeing the requirements for achieving superconductivity. Other parameters are fixed for this case study. Detailed information about the parameters and objective can be found in $[98,99]$.

Figure 9 illustrates the optimization results of SOM by using these three models. As shown, RBF model requires 5 optimization loops to output the final optimum, while the other two models only need 4 loops to converge [6]. Table 4 lists the final optimal results. For the purpose of a sound comparison, the direct optimization results of DEA with FEM are listed in the table as well.

As shown in the Figure, though the RBF model has the smallest optimum for the first loop of SOM, the differences among the optimal results of three models are small. In the first optimization loop of SOM, the same samples are used to derive the models, then DEA is employed for optimization to find the ideal result. After the convergence of the SOM, the difference among the considered approaches becomes relatively small, and the overall best results are achieved for the ANN-based approach. Regarding the required number of samples evaluated through FEA, the combination of SOM and any of these modeling approaches necessitates approximately 200 samples, which are less than $10 \%$ of that required by the direct DEA optimization (2310 evaluations). Therefore, such approaches are effective for optimization and facilitate minimizing the computational cost and the corresponding runtime.

More importantly, there is no big difference between different models with SOM. Therefore, it can be concluded that the optimization strategy may be more important than the particular modeling approach for the optimization of electromagnetic devices. For high-dimensional problems, this conclusion has been confirmed by further studies [47,48]. 


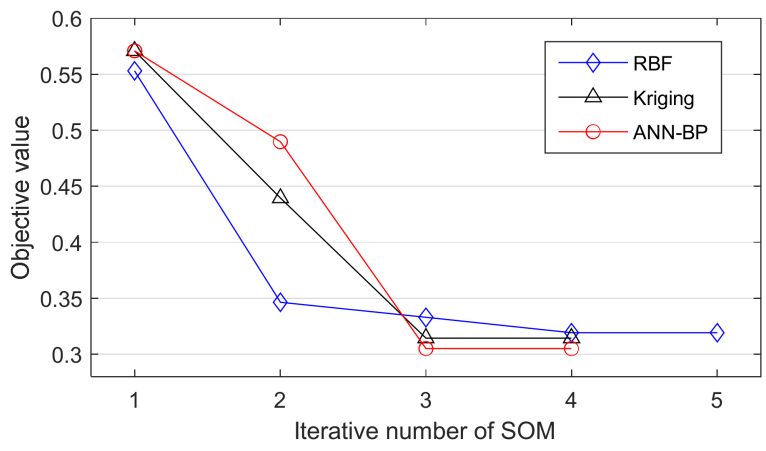

Figure 9. Convergence processes of sequential optimization method (SOM) with three surrogate models (RBF, Kriging, and ANN) for the optimization of SMES.

Table 4. Optimization results of SMES with different models.

\begin{tabular}{cccccc}
\hline Par. & Unit & DEA & RBF & Kriging & ANN-BP \\
\hline$R_{2}$ & $\mathrm{~m}$ & 3.18 & 3.16 & 3.11 & 3.10 \\
$h_{2} / 2$ & $\mathrm{~m}$ & 0.428 & 0.365 & 0.267 & 0.232 \\
$d_{2}$ & $\mathrm{~m}$ & 0.211 & 0.244 & 0.340 & 0.394 \\
$B_{\text {stray }}$ & $\mathrm{mT}$ & 1.032 & 0.957 & 0.943 & 0.938 \\
$E$ & $\mathrm{MJ}$ & 180.00 & 179.95 & 179.94 & 179.94 \\
$F$ & - & 0.344 & 0.319 & 0.315 & 0.313 \\
FEM & - & 2310 & 202 & 157 & 159 \\
\hline
\end{tabular}

\section{Future Directions}

Based on the above discussions, it can be seen that there are many opportunities as well as challenges for the application of machine learning to the design optimization of electromagnetic devices. Compared with conventional design optimization work (including design optimization based on RSM, RBF, and Kriging), the activity of machine-learningbased optimization is very limited, as can be seen from Table 2. It is expected that there is a significant increase of corresponding research activities in the future. We think the following topics require further studies:

\subsection{DL for Field Estimation or Multiphysics Analysis}

DL has been successfully employed to estimate the electromagnetic field distribution and temperature distribution of transformers and PM motors, and the efficiency of PM motors. Due to the nature of high nonlinearity, more studies can be conducted to estimate other field distributions for structure analysis. The field estimation of multi-physics analysis is challenging for this aspect, especially a coupled field analysis, as for instance required for the in-wheel motors and high-speed motors. If multi-physics performance can be predicted accurately by using DL techniques, this will greatly benefit the optimization work.

\subsection{Machine Learning for System-Level Design Optimization of Electrical Drive Systems}

Machine learning algorithms have been used to optimize the dimensions of several electrical machines, like PM motors. They can be used to design the whole electrical drive systems, including both electrical machines and their power electronics, and control systems. Recently, DL has been successfully employed to design the controller to drive the electrical machines $[154,155]$. As there are many types of control algorithms, such as field-oriented control, direct torque control, and model predictive control, more research work shall be conducted.

Currently, selected machine learning approaches do not show significant advances for solving particular optimization problems involving electromagnetic devices when compared with conventional parametric and semi-parametric modeling techniques. The main reason is that their effectiveness depends on the complexity of the considered optimization 
problems, which, for instance, is a function of the number of parameters to be optimized. In case the number of design parameters and objectives and, consequently, the overall complexity of the analysis increases, machine learning algorithms typically feature promising opportunities and feature crucial benefits, e.g., for the system-level multidisciplinary design optimization of electrical drive systems for (hybrid) EVs.

\subsection{Machine Learning for Reliability Improvement of Electromagnetic Devices}

High reliability, especially lifetime reliability, is crucial to all electromagnetic devices. Besides the monitoring of devices' operational status, some important work can be done in the stage of design optimization. Many techniques/methods have to be integrated, such as robust topology design optimization, robust tolerance design optimization [156], and multidisciplinary design optimization. Besides the performance modeling, aspects of the manufacturing and the process itself should be considered within the design optimization, like the integrated product and process development of electric drives using a knowledgebased system [157].

Another important technology is the digital twin. Digital twin is an emerging and fastgrowing technology which connects the physical and virtual world. It has attracted much attention worldwide recently [158-160]. The future of product and service design will be hugely impacted by digital twin technology. With the help of digital twin, the reliability of the product can be controlled with more freedom. Regarding the design optimization of electromagnetic devices, it may have benefits in three main aspects, product development (design process), manufacturing/production, and operation and management. In the design process, digital twin can be used to test the virtual design scheme given by optimization. Thus, possible design defects can be avoided/corrected in the early design stage of electromagnetic devices. Regarding the production process, digital twin can be applied to determine the best manufacturing process (including product chain and quality control). This will increase the robustness and production efficiency and decrease the production cost of the electromagnetic devices. Regarding the operation and management, digital twin can be employed to find out the best control strategy and parameters for electromagnetic devices, like offshore wind generators, to increase their lifetime reliability.

\subsection{Data-Driven Design Optimization Based on Cloud Services}

Considering the characteristics and benefits of the technologies mentioned above, a datadriven design optimization platform can be developed based on industrial big data (material data and manufacturing data) and available cloud services (cloud computing [14,161] and manufacturing). In the future, the optimal design of an electromagnetic device should include the best topology, shape, dimension, and material, and the most appropriate manufacturing process. Reliability-based design and analysis results should be available by evaluating a multidisciplinary analysis model and digital twin technology. Machine learning, especially deep learning, will play an important role in this process.

\section{Conclusions}

This paper reviewed the recent developments in design optimization of electromagnetic devices, with a focus on the application of machine learning algorithms. Through the discussions, it is found that there are many challenges and promising opportunities for the design optimization of electromagnetic devices, with the fast development of advanced machine learning algorithms and intelligent manufacturing technology. Besides the requirements of high performance, there are some challenging objectives for the design optimization of electromagnetic devices, including high lifetime reliability, high robustness, and manufacturing quality and flexibility. To address these challenges, there are promising opportunities for the applications of machine learning algorithms and some modern technologies like digital twin. As investigated in Section 4, machine learning algorithms, such as SVM and DL, revealed very good accuracy in performance prediction of electromagnetic devices, e.g., regarding the estimation of torque and efficiency. DL algorithms are superior 
to predict the distribution of the magnetic field and temperature. Due to their excellent suitability for modeling nonlinear characteristics, more extensive research activities on machine learning algorithms are expected in the future. Four promising research directions are presented, including the application of cloud services and digital twin, to achieve the intelligent design and manufacturing of electromagnetic devices with the consideration of lifetime performance and reliability control.

Author Contributions: Conceptualization, Y.L. and G.L.; writing-original draft preparation, Y.L., S.P. and X.S.; writing-review and editing, G.L. and G.B.; supervision, J.Z. All authors have read and agreed to the published version of the manuscript.

Funding: This work was supported in part by the National Natural Science Foundation of China (NSFC) under grant 61873292, and in part by the Education Department of Henan Province under project 19A470005.

Institutional Review Board Statement: Not applicable.

Informed Consent Statement: Not applicable.

Data Availability Statement: Data is contained within the article.

Conflicts of Interest: The authors declare no conflict of interest.

\section{References}

1. Mohammed, O.A.; Lowther, D.A.; Lean, M.H.; Alhalabi, B. On the creation of a generalized design optimization environment for electromagnetic devices. IEEE Trans. Magn. 2001, 37, 3562-3565. [CrossRef]

2. Sarlioglu, B.; Morris, C.T. More Electric Aircraft: Review, Challenges, and Opportunities for Commercial Transport Aircraft. IEEE Trans. Transp. Electrif. 2015, 1, 54-64. [CrossRef]

3. Khan, A.; Lowther, D.A. Machine Learning applied to the Design and Analysis of Low Frequency Electromagnetic Devices. In Proceedings of the 2020 21st International Symposium on Electrical Apparatus \& Technologies (SIELA), Bourgas, Bulgaria, 3-6 June 2020; pp. 1-4.

4. Duan, Y.; Ionel, D.M. A Review of Recent Developments in Electrical Machine Design Optimization Methods With a PermanentMagnet Synchronous Motor Benchmark Study. IEEE Trans. Ind. Appl. 2013, 49, 1268-1275. [CrossRef]

5. Bramerdorfer, G.; Tapia, J.A.; Pyrhönen, J.J.; Cavagnino, A. Modern Electrical Machine Design Optimization: Techniques, Trends, and Best Practices. IEEE Trans. Ind. Electron. 2018, 65, 7672-7684. [CrossRef]

6. Lei, G.; Zhu, J.; Guo, Y. Multidisciplinary Design Optimization Methods for Electrical Machines and Drive Systems; Springer: Berlin/Heidelberg, Germany, 2016.

7. Hoorfar, A. Evolutionary Programming in Electromagnetic Optimization: A Review. IEEE Trans. Antennas Propag. 2007, 55, 523-537. [CrossRef]

8. Du, G.; Huang, N.; Zhao, Y.; Lei, G.; Zhu, J. Comprehensive Sensitivity Analysis and Multiphysics Optimization of the Rotor for a High Speed Permanent Magnet Machine. IEEE Trans. Energy Convers. 2020. [CrossRef]

9. Koronides, A.; Krasopoulos, C.; Tsiakos, D.; Pechlivanidou, M.S.; Kladas, A. Particular Coupled Electromagnetic, Thermal, Mechanical Design of High-Speed Permanent-Magnet Motor. IEEE Trans. Magn. 2020, 56, 1-5. [CrossRef]

10. Xiao, S.; Li, Y.; Rotaru, M.; Sykulski, J.K. Six Sigma Quality Approach to Robust Optimization. IEEE Trans. Magn. 2015, 51, 1-4. [CrossRef]

11. Ren, Z.; Cho, H.; Yeon, J.; Koh, C. A New Reliability Analysis Algorithm with Insufficient Uncertainty Data for Optimal Robust Design of Electromagnetic Devices. IEEE Trans. Magn. 2015, 51, 1-4. [CrossRef]

12. Ho, S.L.; Yang, S.; Bai, Y.; Li, Y. A Wind Driven Optimization-Based Methodology for Robust Optimizations of Electromagnetic Devices under Interval Uncertainty. IEEE Trans. Magn. 2017, 53, 1-4. [CrossRef]

13. Bramerdorfer, G.; Lei, G.; Cavagnino, A.; Zhang, Y.; Sykulski, J.; Lowther, D.A. More Robust and Reliable Optimized Energy Conversion Facilitated through Electric Machines, Power Electronics and Drives, and Their Control: State-of-the-Art and Trends. IEEE Trans. Energy Convers. 2020, 35, 1997-2012. [CrossRef]

14. Lei, G.; Zhu, J.; Guo, Y.; Liu, C.; Ma, B. A Review of Design Optimization Methods for Electrical Machines. Energies 2017, 10, 1962. [CrossRef]

15. Ma, B.; Lei, G.; Zhu, J.; Guo, Y.; Liu, C. Application-Oriented Robust Design Optimization Method for Batch Production of Permanent-Magnet Motors. IEEE Trans. Ind. Electron. 2018, 65, 1728-1739. [CrossRef]

16. Soares, G.L.; Adriano, R.L.S.; Maia, C.A.; Jaulin, L.; Vasconcelos, J.A. Robust Multi-Objective TEAM 22 Problem: A Case Study of Uncertainties in Design Optimization. IEEE Trans. Magn. 2009, 45, 1028-1031. [CrossRef]

17. Lebensztajn, L.; Coulomb, J. TEAM workshop problem 25: A multi-objective analysis. IEEE Trans. Magn. 2004, 40, 1402-1405. [CrossRef] 
18. Seo, M.; Ryu, N.; Min, S. Sensitivity Analysis for Multi-Objective Optimization of the Benchmark TEAM Problem. IEEE Trans. Magn. 2020, 56, 1-4. [CrossRef]

19. Ali, M.H.; Wu, B.; Dougal, R.A. An Overview of SMES Applications in Power and Energy Systems. IEEE Trans. Sustain. Energy 2010, 1, 38-47. [CrossRef]

20. Rahman, O.; Muttaqi, K.M.; Sutanto, D. High Temperature Superconducting Devices and Renewable Energy Resources in Future Power Grids: A Case Study. IEEE Trans. Appl. Supercond. 2019, 29, 1-4. [CrossRef]

21. Lei, G.; Liu, C.; Jafari, M.; Zhu, J.; Guo, Y. Multilevel Robust Design Optimization of a Superconducting Magnetic Energy Storage Based on a Benchmark Study. IEEE Trans. Appl. Supercond. 2016, 26, 1-5. [CrossRef]

22. Alotto, P.; Baumgartner, U.; Freschi, F.; Jaindl, M.; Kostinger, A.; Magele, C.; Renhart, W.; Repetto, M. SMES Optimization Benchmark Extended: Introducing Pareto Optimal Solutions into TEAM22. IEEE Trans. Magn. 2008, 44, 1066-1069. [CrossRef]

23. Guimaraes, F.G.; Campelo, F.; Saldanha, R.R.; Igarashi, H.; Takahashi, R.H.C.; Ramirez, J.A. A multi-objective proposal for the TEAM benchmark problem 22. IEEE Trans. Magn. 2006, 42, 1471-1474. [CrossRef]

24. Yang, S.; Yang, J.; Bai, Y.; Ni, G. A New Methodology for Robust Optimizations of Optimal Design Problems Under Interval Uncertainty. IEEE Trans. Magn. 2016, 52, 1-4. [CrossRef]

25. Yang, W.; Ho, S.L.; Yang, S. An Efficient Direct Search Methodology for Robust Optimization of Electromagnetic Devices. IEEE Trans. Magn. 2018, 54,1-4. [CrossRef]

26. Sarker, P.; Islam, M.; Guo, Y.; Zhu, J.; Lu, H. State-of-the-Art Technologies for Development of High Frequency Transformers with Advanced Magnetic Materials. IEEE Trans. Appl. Supercond. 2019, 29, 1-11. [CrossRef]

27. Liu, X.; Wang, Y.; Zhu, J.; Guo, Y.; Lei, G.; Liu, C. Calculation of Capacitance in High-Frequency Transformer Windings. IEEE Trans. Magn. 2016, 52,1-4. [CrossRef]

28. Jafari, M.; Malekjamshidi, Z.; Lei, G.; Wang, T.; Platt, G.; Zhu, J. Design and Implementation of an Amorphous High-Frequency Transformer Coupling Multiple Converters in a Smart Microgrid. IEEE Trans. Ind. Electron. 2017, 64, 1028-1037. [CrossRef]

29. Yi, Z.; Sun, K.; Lu, S.; Cao, G.; Li, Y.; Ha, J.I. High-Precision Simulation for Structure and Efficiency Optimization of High-Power High-Frequency Transformer. In Proceedings of the 2020 IEEE Energy Conversion Congress and Exposition (ECCE), Detroit, MI, USA, 11-15 October 2020; pp. 3524-3531.

30. Zhang, K.; Chen, W.; Cao, X.; Song, Z.; Qiao, G.; Sun, L. Optimization Design of High-Power High-Frequency Transformer Based on Multi-Objective Genetic Algorithm. In Proceedings of the 2018 IEEE International Power Electronics and Application Conference and Exposition (PEAC), Shenzhen, China, 4-7 November 2018; pp. 1-5.

31. Islam, M.R.; Lei, G.; Guo, Y.; Zhu, J. Optimal Design of High-Frequency Magnetic Links for Power Converters Used in GridConnected Renewable Energy Systems. IEEE Trans. Magn. 2014, 50, 1-4. [CrossRef]

32. Bastiaens, K.; Krop, D.C.J.; Jumayev, S.; Lomonova, E.A. Optimal Design and Comparison of High-Frequency Resonant and Non-Resonant Rotary Transformers. Energies 2020, 13, 929. [CrossRef]

33. Chau, K.T.; Chan, C.C.; Liu, C. Overview of Permanent-Magnet Brushless Drives for Electric and Hybrid Electric Vehicles. IEEE Trans. Ind. Electron. 2008, 55, 2246-2257. [CrossRef]

34. Zhu, Z.Q.; Howe, D. Electrical Machines and Drives for Electric, Hybrid, and Fuel Cell Vehicles. Proc. IEEE 2007, 95, 746-765. [CrossRef]

35. Sun, X.; Shi, Z.; Lei, G.; Guo, Y.; Zhu, J. Multi-Objective Design Optimization of an IPMSM Based on Multilevel Strategy. IEEE Trans. Ind. Electron. 2021, 68, 139-148. [CrossRef]

36. Cho, S.; Jung, K.; Choi, J. Design Optimization of Interior Permanent Magnet Synchronous Motor for Electric Compressors of Air-Conditioning Systems Mounted on EVs and HEVs. IEEE Trans. Magn. 2018, 54, 1-5. [CrossRef]

37. Lim, D.; Yi, K.; Jung, S.; Jung, H.; Ro, J. Optimal Design of an Interior Permanent Magnet Synchronous Motor by Using a New Surrogate-Assisted Multi-Objective Optimization. IEEE Trans. Magn. 2015, 51, 1-4. [CrossRef]

38. Sun, X.; Shi, Z.; Cai, Y.; Lei, G.; Guo, Y.; Zhu, J. Driving-Cycle-Oriented Design Optimization of a Permanent Magnet Hub Motor Drive System for a Four-Wheel-Drive Electric Vehicle. IEEE Trans. Transp. Electrif. 2020, 6, 1115-1125. [CrossRef]

39. Sun, X.; Hu, C.; Lei, G.; Guo, Y.; Zhu, J. State Feedback Control for a PM Hub Motor Based on Gray Wolf Optimization Algorithm. IEEE Trans. Power Electron. 2020, 35, 1136-1146. [CrossRef]

40. Sun, X.; Shi, Z.; Lei, G.; Guo, Y.; Zhu, J. Analysis and Design Optimization of a Permanent Magnet Synchronous Motor for a Campus Patrol Electric Vehicle. IEEE Trans. Veh. Technol. 2019, 68, 10535-10544. [CrossRef]

41. Wu, D.; Xiang, Z.; Zhu, X.; Quan, L.; Jiang, M.; Liu, Y. Optimization Design of Power Factor for an In-Wheel Vernier PM Machine from Perspective of Air-gap Harmonic Modulation. IEEE Trans. Ind. Electron. 2020. [CrossRef]

42. Coenen, I.; Giet, M.v.d.; Hameyer, K. Manufacturing Tolerances: Estimation and Prediction of Cogging Torque Influenced by Magnetization Faults. IEEE Trans. Magn. 2012, 48, 1932-1936. [CrossRef]

43. Khan, M.A.; Husain, I.; Islam, M.R.; Klass, J.T. Design of Experiments to Address Manufacturing Tolerances and Process Variations Influencing Cogging Torque and Back EMF in the Mass Production of the Permanent-Magnet Synchronous Motors. IEEE Trans. Ind. Appl. 2014, 50, 346-355. [CrossRef]

44. Simón-Sempere, V.; Burgos-Payán, M.; Cerquides-Bueno, J. Influence of Manufacturing Tolerances on the Electromotive Force in Permanent-Magnet Motors. IEEE Trans. Magn. 2013, 49, 5522-5532. [CrossRef]

45. Bramerdorfer, G. Effect of the Manufacturing Impact on the Optimal Electric Machine Design and Performance. IEEE Trans. Energy Convers. 2020, 35, 1935-1943. [CrossRef] 
46. Bramerdorfer, G. Tolerance Design Optimization: Classification, Modeling and Evaluation, and Example. IEEE Trans. Magn. 2019. [CrossRef]

47. Lei, G.; Bramerdorfer, G.; Liu, C.; Guo, Y.; Zhu, J. Robust Design Optimization of Electrical Machines: A Comparative Study and Space Reduction Strategy. IEEE Trans. Energy Convers. 2020. [CrossRef]

48. Lei, G.; Bramerdorfer, G.; Ma, B.; Guo, Y.; Zhu, J. Robust Design Optimization of Electrical Machines: Multi-objective Approach. IEEE Trans. Energy Convers. 2020. [CrossRef]

49. Ma, B.; Zheng, J.; Zhu, J.; Wu, J.; Lei, G.; Guo, Y. Robust Design Optimization of Electrical Machines Considering Hybrid Random and Interval Uncertainties. IEEE Trans. Energy Convers. 2020, 35, 1815-1824. [CrossRef]

50. Ren, Z.; Pham, M.; Koh, C.S. Robust Global Optimization of Electromagnetic Devices With Uncertain Design Parameters: Comparison of the Worst Case Optimization Methods and Multi-objective Optimization Approach Using Gradient Index. IEEE Trans. Magn. 2013, 49, 851-859. [CrossRef]

51. Ren, Z.; Pham, M.; Song, M.; Kim, D.; Koh, C.S. A Robust Global Optimization Algorithm of Electromagnetic Devices Utilizing Gradient Index and Multi-Objective Optimization Method. IEEE Trans. Magn. 2011, 47, 1254-1257. [CrossRef]

52. Ren, Z.; Zhang, D.; Koh, C. New Reliability-Based Robust Design Optimization Algorithms for Electromagnetic Devices Utilizing Worst Case Scenario Approximation. IEEE Trans. Magn. 2013, 49, 2137-2140. [CrossRef]

53. Ren, Z.; Park, C.; Koh, C. Numerically Efficient Algorithm for Reliability-Based Robust Optimal Design of TEAM Problem 22. IEEE Trans. Magn. 2014, 50, 661-664. [CrossRef]

54. Song, J.; Dong, F.; Zhao, J.; Lu, S.; Dou, S.; Wang, H. Optimal design of permanent magnet linear synchronous motors based on Taguchi method. IET Electr. Power Appl. 2017, 11, 41-48. [CrossRef]

55. Credo, A.; Fabri, G.; Villani, M.; Popescu, M. A Robust Design Methodology for Synchronous Reluctance Motors. IEEE Trans. Energy Convers. 2020, 35, 2095-2105. [CrossRef]

56. Lei, G.; Liu, C.; Li, Y.; Chen, D.; Guo, Y.; Zhu, J. Robust Design Optimization of a High-Temperature Superconducting Linear Synchronous Motor Based on Taguchi Method. IEEE Trans. Appl. Supercond. 2019, 29, 1-6. [CrossRef]

57. Dong, F.; Zhao, J.; Song, J.; Zhao, J.; Yao, Z. Robust Design Optimization of Permanent Magnet Linear Synchronous Motor Based on Quantified Constraint Satisfaction Problem. IEEE Trans. Energy Convers. 2020, 35, 2013-2024. [CrossRef]

58. Dong, F.; Zhao, J.; Zhao, J.; Song, J.; Chen, J.; Zheng, Z. Robust Optimization of PMLSM Based on a New Filled Function Algorithm with a Sigma Level Stability Convergence Criterion. IEEE Trans. Ind. Inform. 2020. [CrossRef]

59. Zhu, X.; Yang, J.; Xiang, Z.; Jiang, M.; Zheng, S.; Quan, L. Robust-Oriented Optimization Design for Permanent Magnet Motors Considering Parameter Fluctuation. IEEE Trans. Energy Convers. 2020, 35, 2066-2075. [CrossRef]

60. Kim, S.; Lee, S.G.; Kim, J.M.; Lee, T.H.; Lim, M.S. Robust Design Optimization of Surface-Mounted Permanent Magnet Synchronous Motor Using Uncertainty Characterization by Bootstrap Method. IEEE Trans. Energy Convers. 2020, 35, $2056-2065$. [CrossRef]

61. Lee, J.; Hwang, N.; Ryu, H.; Jung, H.; Woo, D. Robust Optimization Approach Applied to Permanent Magnet Synchronous Motor. IEEE Trans. Magn. 2017, 53, 1-4. [CrossRef]

62. Lei, G.; Zhu, J.; Guo, Y.; Shao, K.; Xu, W. Multiobjective Sequential Design Optimization of PM-SMC Motors for Six Sigma Quality Manufacturing. IEEE Trans. Magn. 2014, 50, 717-720. [CrossRef]

63. Lei, G.; Zhu, J.G.; Guo, Y.G.; Hu, J.F.; Xu, W.; Shao, K.R. Robust Design Optimization of PM-SMC Motors for Six Sigma Quality Manufacturing. IEEE Trans. Magn. 2013, 49, 3953-3956. [CrossRef]

64. Xu, L.; Wu, W.; Zhao, W.; Liu, G.; Niu, S. Robust Design and Optimization for a Permanent Magnet Vernier Machine With Hybrid Stator. IEEE Trans. Energy Convers. 2020, 35, 2086-2094. [CrossRef]

65. Liu, X.; Zhao, Y.; Zhu, J.; Chen, Z.; Huang, S. Multi-Objective Robust Optimization of a Dual-Flux-Modulator Magnetic Geared Machine with Hybrid Uncertainties. IEEE Trans. Energy Convers. 2020, 35, 2106-2115. [CrossRef]

66. Guest Editorial: Robust Design and Analysis of Electric Machines and Drives. IEEE Trans. Energy Convers. 2020, 35, 1995-1996. [CrossRef]

67. Barba, P.D.; Dughiero, F.; Forzan, M.; Lowther, D.A.; Mognaschi, M.E.; Sieni, E.; Sykulski, J.K. A Benchmark TEAM Problem for Multi-Objective Pareto Optimization in Magnetics: The Time-Harmonic Regime. IEEE Trans. Magn. 2020, 56, 1-4. [CrossRef]

68. Barba, P.D.; Mognaschi, M.E.; Lowther, D.A.; Sykulski, J.K. A Benchmark TEAM Problem for Multi-Objective Pareto Optimization of Electromagnetic Devices. IEEE Trans. Magn. 2018, 54, 1-4. [CrossRef]

69. Diao, K.; Sun, X.; Lei, G.; Guo, Y.; Zhu, J. Multimode Optimization of Switched Reluctance Machines in Hybrid Electric Vehicles. IEEE Trans. Energy Convers. 2020. [CrossRef]

70. Zhu, X.; Fan, D.; Mo, L.; Chen, Y.; Quan, L. Multiobjective Optimization Design of a Double-Rotor Flux-Switching Permanent Magnet Machine Considering Multimode Operation. IEEE Trans. Ind. Electron. 2019, 66, 641-653. [CrossRef]

71. Zhu, X.; Xiang, Z.; Quan, L.; Wu, W.; Du, Y. Multimode Optimization Design Methodology for a Flux- Controllable Stator Permanent Magnet Memory Motor Considering Driving Cycles. IEEE Trans. Ind. Electron. 2018, 65, 5353-5366. [CrossRef]

72. Bhagubai, P.P.; Sarrico, J.G.; Fernandes, J.F.; Costa Branco, P.J. Design, Multi-Objective Optimization, and Prototyping of a 20 kW $8000 \mathrm{rpm}$ Permanent Magnet Synchronous Motor for a Competition Electric Vehicle. Energies 2020, 13, 2465. [CrossRef]

73. Wu, T.; Feng, Z.; Wu, C.; Lei, G.; Guo, Y.; Zhu, J.; Wang, X. Multiobjective Optimization of a Tubular Coreless LPMSM Based on Adaptive Multiobjective Black Hole Algorithm. IEEE Trans. Ind. Electron. 2020, 67, 3901-3910. [CrossRef] 
74. Ho, S.L.; Yang, J.; Yang, S.; Bai, Y. A Real Coded Vector Population-Based Incremental Learning Algorithm for Multi-Objective Optimizations of Electromagnetic Devices. IEEE Trans. Magn. 2018, 54, 1-4. [CrossRef]

75. Ho, S.L.; Yang, S. A Wind Driven Optimization Algorithm for Global Optimization of Electromagnetic Devices. IEEE Trans. Magn. 2018, 54, 1-5. [CrossRef]

76. Knypiński, Ł.; Pawełoszek, K.; Le Menach, Y. Optimization of Low-Power Line-Start PM Motor Using Gray Wolf Metaheuristic Algorithm. Energies 2020, 13, 1186.

77. Baatar, N.; Jeong, K.; Koh, C. Adaptive Parameter Controlling Non-Dominated Ranking Differential Evolution for Multi-Objective Optimization of Electromagnetic Problems. IEEE Trans. Magn. 2014, 50, 709-712. [CrossRef]

78. Baek, S.-W.; Lee, S.W. Design Optimization and Experimental Verification of Permanent Magnet Synchronous Motor Used in Electric Compressors in Electric Vehicles. Appl. Sci. 2020, 10, 3235. [CrossRef]

79. Dong, F.; Zhao, J.; Song, J.; Feng, Y.; He, Z. Optimal Design of Permanent Magnet Linear Synchronous Motors at Multispeed Based on Particle Swarm Optimization Combined With SN Ratio Method. IEEE Trans. Energy Convers. 2018, 33, $1943-1954$. [CrossRef]

80. Rehman, O.U.; Yang, S.; Khan, S.; Rehman, S.U. A Quantum Particle Swarm Optimizer with Enhanced Strategy for Global Optimization of Electromagnetic Devices. IEEE Trans. Magn. 2019, 55, 1-4. [CrossRef]

81. Zhao, X.; Niu, S. Design and Optimization of a Novel Slot-PM-Assisted Variable Flux Reluctance Generator for Hybrid Electric Vehicles. IEEE Trans. Energy Convers. 2018, 33, 2102-2111. [CrossRef]

82. Lin, Q.; Niu, S.; Fu, W.N. Design and Optimization of a Dual-Permanent-Magnet Vernier Machine With a Novel Optimization Model. IEEE Trans. Magn. 2020, 56, 1-5. [CrossRef]

83. Zhao, X.; Niu, S. Design and Optimization of a New Magnetic-Geared Pole-Changing Hybrid Excitation Machine. IEEE Trans. Ind. Electron. 2017, 64, 9943-9952. [CrossRef]

84. Wang, Q.; Niu, S.; Yang, L. Design Optimization and Comparative Study of Novel Dual-PM Excited Machines. IEEE Trans. Ind. Electron. 2017, 64, 9924-9933. [CrossRef]

85. Yazdani-Asrami, M.; Alipour, M.; Gholamian, S.A. Optimal ECO-Design of Permanent Magnet Brushless DC Motor Using Modified Tabu Search Optimizer and Finite Element Analysis. J. Magn. 2015, 20, 161-165. [CrossRef]

86. Di Noia, L.P.; Piegari, L.; Rizzo, R. Optimization Methodology of PMSM Cooled by External Convection in Aircraft Propulsion. Energies 2020, 13, 3975. [CrossRef]

87. Jabr, R.A. Application of geometric programming to transformer design. IEEE Trans. Magn. 2005, 41, 4261-4269. [CrossRef]

88. Khazaei, S.; Tahani, A.; Yazdani-Asrami, M.; Gholamian, S.A. Optimal Design of Three Phase Surface Mounted Permanent Magnet Synchronous Motor by Particle Swarm optimization and Bees Algorithm for Minimum Volume and Maximum Torque. J. Adv. Comput. Res. 2015, 6, 83-98.

89. Bocii, L.S.; Di Noia, L.P.; Rizzo, R. Optimization of the Energy Storage of Series-Hybrid Propelled Aircraft by Means of Integer Differential Evolution. Aerospace 2019, 6, 59. [CrossRef]

90. Hoburg, W.; Abbeel, P. Geometric programming for aircraft design optimization. AIAA J. 2014, 52, 2414-2426. [CrossRef]

91. Yazdani-Asrami, M.; Taghipour-Gorjikolaie, M.; Song, W.; Zhang, M.; Yuan, W. Prediction of Nonsinusoidal AC Loss of Superconducting Tapes Using Artificial Intelligence-Based Models. IEEE Access 2020, 8, 207287-207297. [CrossRef]

92. Cvetkovski, G.; Petkovska, L.; Gair, S. Specific power as objective function in GA optimal design of permanent magnet disc motor. Compel Int. J. Comput. Math. Electr. Electron. Eng. 2010, 29, 964-973. [CrossRef]

93. Bramerdorfer, G.; Zăvoianu, A. Surrogate-Based Multi-Objective Optimization of Electrical Machine Designs Facilitating Tolerance Analysis. IEEE Trans. Magn. 2017, 53, 1-11. [CrossRef]

94. Wang, L.; Lowther, D.A. Selection of approximation models for electromagnetic device optimization. IEEE Trans. Magn. 2006, 42, 1227-1230 [CrossRef]

95. Zhu, X.; Yan, B.; Chen, L.; Zhang, R.; Quan, L.; Mo, L. Multi-Objective Optimization Design of a Magnetic Planetary Geared Permanent Magnet Brushless Machine by Combined Design of Experiments and Response Surface Methods. IEEE Trans. Magn. 2014, 50, 1-4. [CrossRef]

96. Lebensztajn, L.; Marretto, C.A.R.; Costa, M.C.; Coulomb, J. Kriging: A useful tool for electromagnetic device optimization. IEEE Trans. Magn. 2004, 40, 1196-1199. [CrossRef]

97. Lei, G.; Liu, C.; Zhu, J.; Guo, Y. Techniques for Multilevel Design Optimization of Permanent Magnet Motors. IEEE Trans. Energy Convers. 2015, 30, 1574-1584. [CrossRef]

98. Lei, G.; Shao, K.R.; Guo, Y.; Zhu, J.; Lavers, J.D. Sequential Optimization Method for the Design of Electromagnetic Device. IEEE Trans. Magn. 2008, 44, 3217-3220. [CrossRef]

99. Lei, G.; Shao, K.R.; Guo, Y.; Zhu, J.; Lavers, J.D. Improved Sequential Optimization Method for High Dimensional Electromagnetic Device Optimization. IEEE Trans. Magn. 2009, 45, 3993-3996. [CrossRef]

100. Lei, G.; Yang, G.Y.; Shao, K.R.; Guo, Y.; Zhu, J.; Lavers, J.D. Electromagnetic Device Design Based on RBF Models and Two New Sequential Optimization Strategies. IEEE Trans. Magn. 2010, 46, 3181-3184. [CrossRef]

101. Zhu, X.; Shu, Z.; Quan, L.; Xiang, Z.; Pan, X. Multi-Objective Optimization of an Outer-Rotor V-Shaped Permanent Magnet Flux Switching Motor Based on Multilevel Design Method. IEEE Trans. Magn. 2016, 52, 1-8. [CrossRef]

102. Lei, G.; Guo, Y.G.; Zhu, J.G.; Wang, T.S.; Chen, X.M.; Shao, K.R. System Level Six Sigma Robust Optimization of a Drive System With PM Transverse Flux Machine. IEEE Trans. Magn. 2012, 48, 923-926. [CrossRef] 
103. Lei, G.; Liu, C.; Guo, Y.; Zhu, J. Multidisciplinary Design Analysis and Optimization of a PM Transverse Flux Machine With Soft Magnetic Composite Core. IEEE Trans. Magn. 2015, 51, 1-4. [CrossRef]

104. Lei, G.; Liu, C.; Guo, Y.; Zhu, J. Robust Multidisciplinary Design Optimization of PM Machines With Soft Magnetic Composite Cores for Batch Production. IEEE Trans. Magn. 2016, 52, 1-4. [CrossRef]

105. Lei, G.; Wang, T.; Guo, Y.; Zhu, J.; Wang, S. System-Level Design Optimization Methods for Electrical Drive Systems: Deterministic Approach. IEEE Trans. Ind. Electron. 2014, 61, 6591-6602. [CrossRef]

106. Lei, G.; Wang, T.; Zhu, J.; Guo, Y. Robust multi-objective and multidisciplinary design optimization of electrical drive systems. CES Trans. Electr. Mach. Syst. 2018, 2, 409-416. [CrossRef]

107. Lei, G.; Wang, T.; Zhu, J.; Guo, Y.; Wang, S. System-Level Design Optimization Method for Electrical Drive Systems-Robust Approach. IEEE Trans. Ind. Electron. 2015, 62, 4702-4713. [CrossRef]

108. Lei, G.; Xu, W.; Hu, J.; Zhu, J.; Guo, Y.; Shao, K. Multilevel Design Optimization of a FSPMM Drive System by Using Sequential Subspace Optimization Method. IEEE Trans. Magn. 2014, 50, 685-688. [CrossRef]

109. Diao, K.; Sun, X.; Lei, G.; Bramerdorfer, G.; Guo, Y.; Zhu, J. System-level Robust Design Optimization of a Switched Reluctance Motor Drive System Considering Multiple Driving Cycles. IEEE Trans. Energy Convers. 2020. [CrossRef]

110. Diao, K.; Sun, X.; Lei, G.; Guo, Y.; Zhu, J. Multiobjective System Level Optimization Method for Switched Reluctance Motor Drive Systems Using Finite-Element Model. IEEE Trans. Ind. Electron. 2020, 67, 10055-10064. [CrossRef]

111. Krasopoulos, C.T.; Beniakar, M.E.; Kladas, A.G. Robust Optimization of High-Speed PM Motor Design. IEEE Trans. Magn. 2017, 53, 1-4. [CrossRef]

112. Ma, B.; Zheng, J.; Lei, G.; Zhu, J.; Jin, P.; Guo, Y. Topology Optimization of Ferromagnetic Components in Electrical Machines. IEEE Trans. Energy Convers. 2020, 35, 786-798. [CrossRef]

113. Ho, S.L.; Yang, S.; Bai, Y. A Fast Methodology for Topology Optimizations of Electromagnetic Devices. IEEE Trans. Magn. 2017, 53, 1-4. [CrossRef]

114. Li, Y.; Yang, S.; Ren, Z. A Methodology Based on Quantum Evolutionary Algorithm for Topology Optimization of Electromagnetic Devices. IEEE Trans. Magn. 2019, 55, 1-4. [CrossRef]

115. Yang, W.; Ho, S.L.; Fu, W. A Modified Shuffled Frog Leaping Algorithm for the Topology Optimization of Electromagnet Devices. Appl. Sci. 2020, 10, 6186. [CrossRef]

116. Lolova, I.; Barta, J.; Bramerdorfer, G.; Silber, S. Topology optimization of line-start synchronous reluctance machine. In Proceedings of the 2020 19th International Conference on Mechatronics Mechatronika (ME), Prague, Czech Republic, 2-4 December 2020; pp. 1-7.

117. Liu, B. Theory and Practice of Uncertain Programming, 2nd ed.; Springer: Berlin/Heidelberg, Germany, 2009.

118. Liu, B. Uncertain set theory and uncertain inference rule with application to uncertain control. J. Uncertain Syst. 2010, 4, 83-98.

119. Guimaraes, F.G.; Campelo, F.; Saldanha, R.R.; Ramirez, J.A. A hybrid methodology for fuzzy optimization of electromagnetic devices. IEEE Trans. Magn. 2005, 41, 1744-1747. [CrossRef]

120. Changhwan, C.; Daeok, L.; Kyihwan, P. Fuzzy design of a switched reluctance motor based on the torque profile optimization. IEEE Trans. Magn. 2000, 36, 3548-3550. [CrossRef]

121. Chen, H.; Zhan, Y.; Nie, R. Multiobjective Optimization Design of Single-Phase Tubular Switched Reluctance Linear Launcher. IEEE Trans. Plasma Sci. 2019, 47, 2431-2437. [CrossRef]

122. Chen, H.; Zhan, Y.; Nie, R.; Zhao, S. Multiobjective Optimization Design of Tubular Permanent Magnet Linear Launcher. IEEE Trans. Plasma Sci. 2019, 47, 2486-2492. [CrossRef]

123. Guo, Y.; Si, J.; Gao, C.; Feng, H.; Gan, C. Improved Fuzzy-Based Taguchi Method for Multi-Objective Optimization of Direct-Drive Permanent Magnet Synchronous Motors. IEEE Trans. Magn. 2019, 55, 1-4. [CrossRef]

124. Hwang, C.; Chang, C.; Liu, C. A Fuzzy-Based Taguchi Method for Multiobjective Design of PM Motors. IEEE Trans. Magn. 2013, 49, 2153-2156. [CrossRef]

125. Shi, Z.; Sun, X.; Cai, Y.; Yang, Z. Robust Design Optimization of a Five-Phase PM Hub Motor for Fault-Tolerant Operation Based on Taguchi Method. IEEE Trans. Energy Convers. 2020, 35, 2036-2044. [CrossRef]

126. Sun, X.; Shi, Z.; Zhu, J. Multi-objective Design Optimization of an IPMSM for EVs Based on Fuzzy Method and Sequential Taguchi Method. IEEE Trans. Ind. Electron. 2020. [CrossRef]

127. Dong, F.; Song, J.; Zhao, J.; Zhao, J. Multi-objective design optimization for PMSLM by FITM. IET Electr. Power Appl. 2018, 12, 188-194. [CrossRef]

128. Liu, C.; Lei, G.; Ma, B.; Guo, Y.; Zhu, J. Robust Design of a Low-Cost Permanent Magnet Motor with Soft Magnetic Composite Cores Considering the Manufacturing Process and Tolerances. Energies 2018, 11, 2025. [CrossRef]

129. Khan, A.; Ghorbanian, V.; Lowther, D. Deep Learning for Magnetic Field Estimation. IEEE Trans. Magn. 2019, 55, 1-4. [CrossRef]

130. Kirchgässner, W.; Wallscheid, O.; Böcker, J. Deep Residual Convolutional and Recurrent Neural Networks for Temperature Estimation in Permanent Magnet Synchronous Motors. In Proceedings of the 2019 IEEE International Electric Machines \& Drives Conference (IEMDC), San Diego, CA, USA, 12-15 May 2019; pp. 1439-1446.

131. Kirchgassner, W.; Wallscheid, O.; Boecker, J. Estimating Electric Motor Temperatures with Deep Residual Machine Learning. IEEE Trans. Power Electron. 2020. [CrossRef]

132. Khan, A.; Mohammadi, M.H.; Ghorbanian, V.; Lowther, D. Efficiency Map Prediction of Motor Drives Using Deep Learning. IEEE Trans. Magn. 2020, 56, 1-4. [CrossRef] 
133. Sun, X.; Wu, J.; Lei, G.; Cai, Y.; Chen, X.; Guo, Y. Torque Modeling of a Segmented-Rotor SRM Using Maximum-CorrentropyCriterion-Based LSSVR for Torque Calculation of EVs. IEEE J. Emerg. Sel. Top. Power Electron. 2020. [CrossRef]

134. Wu, J.; Sun, X.; Zhu, J. Accurate torque modeling with PSO-based recursive robust LSSVR for a segmented-rotor switched reluctance motor. CES Trans. Electr. Mach. Syst. 2020, 4, 96-104. [CrossRef]

135. Li, H.; Cui, L.; Ma, Z.; Li, B. Multi-Objective Optimization of the Halbach Array Permanent Magnet Spherical Motor Based on Support Vector Machine. Energies 2020, 13, 5704. [CrossRef]

136. Zhao, J.; Huang, J.; Wang, Y.; Liu, K. Design optimization of permanent magnet synchronous linear motor by multi-SVM. In Proceedings of the 2014 17th International Conference on Electrical Machines and Systems (ICEMS), Hangzhou, China, 22-25 October 2014; pp. 1279-1282.

137. Arnoux, P.; Caillard, P.; Gillon, F. Modeling Finite-Element Constraint to Run an Electrical Machine Design Optimization Using Machine Learning. IEEE Trans. Magn. 2015, 51, 1-4. [CrossRef]

138. Song, J.; Dong, F.; Zhao, J.; Wang, H.; He, Z.; Wang, L. An Efficient Multiobjective Design Optimization Method for a PMSLM Based on an Extreme Learning Machine. IEEE Trans. Ind. Electron. 2019, 66, 1001-1011. [CrossRef]

139. Song, J.; Zhao, J.; Dong, F.; Zhao, J.; Qian, Z.; Zhang, Q. A Novel Regression Modeling Method for PMSLM Structural Design Optimization Using a Distance-Weighted KNN Algorithm. IEEE Trans. Ind. Appl. 2018, 54, 4198-4206. [CrossRef]

140. You, Y.-M. Multi-Objective Optimal Design of Permanent Magnet Synchronous Motor for Electric Vehicle Based on Deep Learning. Appl. Sci. 2020, 10, 482. [CrossRef]

141. Wang, W.; Zhao, J.; Zhou, Y.; Dong, F. New optimization design method for a double secondary linear motor based on R-DNN modeling method and MCS optimization algorithm. Chin. J. Electr. Eng. 2020, 6, 98-105. [CrossRef]

142. Barmada, S.; Fontana, N.; Sani, L.; Thomopulos, D.; Tucci, M. Deep Learning and Reduced Models for Fast Optimization in Electromagnetics. IEEE Trans. Magn. 2020, 56, 1-4. [CrossRef]

143. Sasaki, H.; Igarashi, H. Topology Optimization Accelerated by Deep Learning. IEEE Trans. Magn. 2019, 55, 1-5. [CrossRef]

144. Doi, S.; Sasaki, H.; Igarashi, H. Multi-Objective Topology Optimization of Rotating Machines Using Deep Learning. IEEE Trans. Magn. 2019, 55, 1-5. [CrossRef]

145. Asanuma, J.; Doi, S.; Igarashi, H. Transfer Learning Through Deep Learning: Application to Topology Optimization of Electric Motor. IEEE Trans. Magn. 2020, 56, 1-4. [CrossRef]

146. Li, J.; Water, W.; Zhu, B.; Lu, J. Integrated High-Frequency Coaxial Transformer Design Platform Using Artificial Neural Network Optimization and FEM Simulation. IEEE Trans. Magn. 2015, 51, 1-4. [CrossRef]

147. Wu, Q.; Cao, Y.; Wang, H.; Hong, W. Machine-learning-assisted optimization and its application to antenna designs: Opportunities and challenges. China Commun. 2020, 17, 152-164. [CrossRef]

148. Maeurer, C.; Futter, P.; Gampala, G. Antenna Design Exploration and Optimization using Machine Learning. In Proceedings of the 2020 14th European Conference on Antennas and Propagation (EuCAP), Copenhagen, Denmark, 15-20 March 2020; pp. 1-5.

149. Massa, A.; Marcantonio, D.; Chen, X.; Li, M.; Salucci, M. DNNs as Applied to Electromagnetics, Antennas, and Propagation-A Review. IEEE Antennas Wirel. Propag. Lett. 2019, 18, 2225-2229. [CrossRef]

150. Cui, L.; Zhang, Y.; Zhang, R.; Liu, Q.H. A Modified Efficient KNN Method for Antenna Optimization and Design. IEEE Trans. Antennas Propag. 2020, 68, 6858-6866. [CrossRef]

151. Yao, H.M.; Jiang, L.; Zhang, H.H.; Sha, W.E.I. Machine Learning Methodology Review for Computational Electromagnetics. In Proceedings of the 2019 International Applied Computational Electromagnetics Society Symposium China (ACES), Nanjing, China, 8-11 August 2019; pp. 1-4.

152. Erricolo, D.; Chen, P.; Rozhkova, A.; Torabi, E.; Bagci, H.; Shamim, A.; Zhang, X. Machine Learning in Electromagnetics: A Review and Some Perspectives for Future Research. In Proceedings of the 2019 International Conference on Electromagnetics in Advanced Applications (ICEAA), Granada, Spain, 9-13 September 2019; pp. 1377-1380.

153. Akinsolu, M.O.; Mistry, K.K.; Liu, B.; Lazaridis, P.I.; Excell, P. Machine Learning-assisted Antenna Design optimization: A Review and the State-of-the-art. In Proceedings of the 2020 14th European Conference on Antennas and Propagation (EuCAP), Copenhagen, Denmark, 15-20 March 2020; pp. 1-5.

154. Schenke, M.; Kirchgässner, W.; Wallscheid, O. Controller Design for Electrical Drives by Deep Reinforcement Learning: A Proof of Concept. IEEE Trans. Ind. Inform. 2020, 16, 4650-4658. [CrossRef]

155. Traue, A.; Book, G.; Kirchgässner, W.; Wallscheid, O. Toward a Reinforcement Learning Environment Toolbox for Intelligent Electric Motor Control. IEEE Trans. Neural Netw. Learn. Syst. 2020. [CrossRef] [PubMed]

156. Ma, B.; Lei, G.; Liu, C.; Zhu, J.; Guo, Y. Robust Tolerance Design Optimization of a PM Claw Pole Motor With Soft Magnetic Composite Cores. IEEE Trans. Magn. 2018, 54, 1-4. [CrossRef]

157. Mayr, A.; Meyer, A.; Gönnheimer, P.; Gramlich, J.; Reiser, M.; Franke, J. Concept for an integrated product and process development of electric drives using a knowledge-based system. In Proceedings of the 2017 7th International Electric Drives Production Conference (EDPC), Nuremberg, Germany, 5-6 December 2017; pp. 1-7.

158. Orosz, T.; Rassõlkin, A.; Kallaste, A.; Arsénio, P.; Pánek, D.; Kaska, J.; Karban, P. Robust Design Optimization and Emerging Technologies for Electrical Machines: Challenges and Open Problems. Appl. Sci. 2020, 10, 6653. [CrossRef]

159. Schroeder, G.N.; Steinmetz, C.; Rodrigues, R.N.; Henriques, R.V.B.; Rettberg, A.; Pereira, C.E. A Methodology for Digital Twin Modeling and Deployment for Industry 4.0. Proc. IEEE 2020. [CrossRef] 
160. Tao, F.; Sui, F.; Liu, A.; Qi, Q.; Zhang, M.; Song, B.; Guo, Z.; Lu, S.C.Y.; Nee, A.Y.C. Digital twin-driven product design framework. Int. J. Prod. Res. 2019, 57, 3935-3953. [CrossRef]

161. Pliuhin, V.; Pan, M.; Yesina, V.; Sukhonos, M. Using Azure Maching Learning Cloud Technology for Electric Machines Optimization. In Proceedings of the 2018 International Scientific-Practical Conference Problems of Infocommunications. Science and Technology (PIC S\&T), Kharkiv, Ukraine, 9-12 October 2018; pp. 55-58. 